\title{
Nuevos sitios fosilíferos y evolución paleoambiental del Cenozoico tardío del suroeste de Córdoba, Argentina
}

\author{
*Adan Alejo Tauber ${ }^{1,2,3}$, Federico Álvarez ${ }^{3}$, Gastón Martínez ${ }^{2,3,4}$, \\ Augusto Haro 2, 3, 4, Jerónimo Krapovickas ${ }^{1,2,3}$, Gastón Nieto 2, 3,4
}

\author{
I Museo Provincial de Ciencias Naturales "Dr. Arturo Umberto Illia”, Agencia Córdoba Cultura, Poeta Lugones 395, X5000HZD, \\ Córdoba, Argentina. \\ adan.tauber@unc.edu.ar, jeronimokrapovickas@gmail.com \\ 2 Museo de Paleontología, Facultad de Ciencias Exactas, Físicas y Naturales, Universidad Nacional de Córdoba, Vélez Sarsfield \\ 249, X5000JJC, Córdoba, Argentina. \\ gmartinezpsf@gmail.com,augustoharo@unc.edu.ar, gastonleonardonieto@gmail.com \\ 3 Cátedra de Paleontología, Facultad de Ciencias Exactas, Físicas y Naturales, Universidad Nacional de Córdoba, Vélez Sarsfield \\ 1611, X5016GCA, Córdoba, Argentina. \\ irnefer@hotmail.com \\ ${ }^{4}$ Consejo Nacional de Investigaciones Cientificas y Técnicas (CONICET), Godoy Cruz 2290, C1425FQB, Buenos Aires, Argentina.
}

* Autor para correspondencia: adan.tauber@unc.edu.ar

RESUMEN. Nuevos restos fósiles fueron hallados en secuencias sedimentarias neógenas y cuaternarias que afloran en las localidades de Alpa Corral y río San Bartolomé (departamento de Río Cuarto, provincia de Córdoba). Estos fueron asignados a Nopachtus cabrerai (Xenarthra, Cingulata, Glyptodontidae), Notiomastodon platensis (Proboscidea, Gomphotheriidae) y cf. Trigodon gaudryi (Notoungulata, Toxodontidae), y se identificaron trazas de la icnofacies de Scoyenia como Taenidium barretti. Sobre la base de estos registros se concluye: 1. las especies Nopachtus cabrerai y cf. Trigodon gaudryi se registran por primera vez en la región de las Sierras Pampeanas y se suman al conjunto de taxones que indican una clara similitud faunística con la región Pampeana; 2. el inicio de la sedimentación neógena en la región de Alpa Corral (valle del río de Las Barrancas y río San Bartolomé) habría comenzado durante el Plioceno temprano (Edad Montehermosense); 3. el paleoambiente habría sido un sistema fluvial con canales meandriformes, intercalados con paleosuelos desarrollados en llanuras de inundación con depósitos de desborde o meandros abandonados; 4. el registro paleontológico y sedimentario sugiere un diacronismo muy marcado en el inicio de la depositación neógena (con dirección oeste a este), entre el sector sur del valle de San Alberto (Mioceno tardío; Edad Huayqueriense), en la región de Alpa Corral (Plioceno temprano; Edad Montehermosense), y el valle del río de La Cruz (Plioceno tardío; Edad Chapadmalalense). 


\begin{abstract}
New fossiliferous sites and late Cenozoic paleoenvironmental evolution of southwestern Córdoba, Argentina. New fossil remains were found in Neogene and quaternary sedimentary sequences exposed in Alpa Corral and río San Bartolomé localities (Río Cuarto Department, Córdoba, Argentina). They were assigned to Nopachtus cabrerai (Xenarthra, Cingulata, Glyptodontidae), Notiomastodon platensis (Proboscidea, Gomphotheriidae) and cf. Trigodon gaudryi (Notoungulata, Toxodontidae), and traces of the Scoyenia ichnofacies, as Taenidium barretti, were identified. Based on these findings, we conclude that: 1. the species Nopachtus cabrerai and cf. Trigodon gaudryi are registered for the first time in the Sierras Pampeanas region and support (along with the rest of the known taxa) a clear faunistic similarity to the Pampean region; 2. the beginning of the Neogene sedimentation in the Alpa Corral area (Las Barrancas river and San Bartolome river) would have started during the early Pliocene (Montehermosan Age); 3. the paleoenvironment would have been a fluvial system, with meandering canals interspersed with paleosols developed in floodplains with overflow deposits or abandoned meanders; 4 . the paleontological and sedimentary record suggests a well-marked diachronism (from west to east) between the beginning of the Neogene sedimentation in the southern sector of San Alberto valley (late Miocene [Huayquerian Age]), the Alpa Corral region (early Pliocene [Monthermosan Age]), and Río La Cruz valley (late Pliocene [Chapadmalalan Age]).
\end{abstract}

Keywords: Early Pliocene, Pleistocene, Paleoenvironmet, Montehermosan, Sierras Pampeanas of Córdoba, Mammals, Argentina.

\section{Introducción}

Los depósitos sedimentarios neógenos y cuaternarios de las Sierras de Córdoba resultan de particular interés, debido a la información que podemos obtener de ellos para comprender el origen y la evolución geológica de sus principales valles y cordones montañosos, como consecuencia de la deformación de la corteza terrestre originada por la subducción horizontal de la placa de Nazca a partir del Mioceno (e.g., Ramos y Folguera, 2016; Poma et al., 2017; Suriano et al., 2017). Esta deformación no solo se refiere a la génesis de las diferentes cuencas interserranas o depocentros y las distintas condiciones geológicas y ambientales de depositación, sino al impacto y control que estos ambientes habrían ocasionado sobre la biota y su evolución. Entre los factores que se destacan como controladores de la distribución de la vegetación en regiones montañosas, está el relieve topográfico vinculado con las diferencias de alturas y pendientes (directamente relacionado con las variaciones de insolación, humedad, temperatura y escurrimiento) y la composición química y mineralógica y la estructura física del suelo, los que intervienen en los patrones de erosión, fracturación o exfoliación en el caso de los sustratos rocosos, y su influencia sobre el tipo de escurrimiento.

Por estos motivos, las áreas montañosas y rocosas representan en general ambientes heterogéneos, con elevada biodiversidad y, con frecuencia, son asiento de comunidades únicas con altos niveles de endemismo (Smith y Cleef, 1988; Barthlott et al., 1993; Alves y Kolbek, 1994; Porembski et al., 1994, 1996;
Giulietti et al., 1997, 2005; Michelangeli, 2000; Jacobi y Carmo, 2008a, b). Además, pueden formar barreras ecológicas controladas por diversos factores ambientales para las especies, sobre todo para los vegetales (Larson et al., 2008), y son hábitats singulares que tienen un papel muy importante como refugios de especies poco frecuentes o en retracción (Wardle, 1971, 1991; Rogers y Walker, 2002; Burke et al., 2003; Hunter, 2003; de Lange et al., 2004; Wiser y Buxton, 2009; Esgario et al., 2009; Sadler y Bradfield, 2010). La evidencia sugiere que existe una estrecha relación entre las asociaciones de vegetales y el tipo de litología del sustrato (rocas carbonáticas, serpentinitas y basaltos) de las Sierras de Córdoba (Cantero, 2018; Cantero et al., 2011, 2014a, b, c, 2016, 2017a, b).

En este contexto, el análisis de facies sedimentarias del Cenozoico tardío (especialmente de edad neógena) de las Sierras Pampeanas Orientales y sus piedemontes resulta primordial, no solo para avanzar en los temas mencionados en los párrafos precedentes, sino también para lograr una visión integradora y regional del registro geológico y paleontológico. Paradógicamente, y luego de 145 años de investigaciones (Burmeister, 1874; Tauber et al., 2019a), parece no haber consenso acerca de la antigüedad precisa y las correlaciones lito- y bioestratigráficas de los depósitos sedimentarios neógenos de los diferentes valles y áreas pedemontanas de esta región.

Cruz et al. (2017) brindaron una síntetisis de las propuestas de diferentes autores que indagaron al respecto (Castellanos, 1942, 1944, 1958; Sayago, 1978; Gordillo y Lencinas, 1979; Marshall et al., 
1983, 1984; Cantú, 1992; Berman, 1994; Bond et al., 1995; Cione y Tonni, 1995a, b; Bond, 1999; Bonalumi et al., 2000; Álvarez y Tauber, 2003, 2004; Cruz, 2011, 2013; Astini et al., 2014; Tauber et al., 2014, 2018, 2019a, b, entre otros), quienes sugirieron, para los depósitos neógenos denominados Formación Brochero u "Horizonte Brocherense" (Castellanos, 1942, 1944; Sayago, 1978), edades que abarcan desde el Mioceno tardío (Edad Huayqueriense) hasta el Pleistoceno Temprano y Medio (Edad Ensenadense).

En este contexto, los procesos asociados con el inicio de la sedimentación neógena en toda la vertiente oriental de las Sierras Chicas, Sierra de Achala y Sierra de los Comechingones en general, son claves para comprender la evolución geológica y biótica de las Sierras Pampeanas durante el proceso de subducción y horizontalización de la placa de Nazca. Una zona particularmente relevante es la localidad de Alpa Corral y alrededores, departamento Río Cuarto, provincia de Córdoba, situada en el límite entre la vertiente oriental de la Sierra de los Comechingones y su piedemonte (Figs. 1 y 2).

La importancia de esta región radica en al menos tres puntos principales; (1) en cercanías a la localidad de Alpa Corral se encuentra el afloramiento fosilífero neógeno más austral registrado en la vertiente oriental de la Sierra de los Comechingones y en toda la provincia de Córdoba, (2) la antigüedad de las diferentes unidades fue asignada fundamentalmente por correlaciones litoestratigráficas regionales y por algunos pocos mamíferos fósiles hallados e insuficientemente documentados desde el punto de vista bioestratigráfico (Giannoncelli y Tauber, 1997; Degiovanni et al., 2005; Tauber et al., 2014; Tauber et al., 2019a, b), y (3) allí se encuentra el área tipo de la Formación Alpa Corral (Cantú, 1992). Respecto de este último punto, el autor la correlacionó con la Formación Estancia Belgrano (Santa Cruz, 1972, 1973) y con la Formación Brochero (Sayago, 1978), mientras que Combina y Sánchez (2003) la correlacionaron también con la unidad informal "Conglomerados" (Sanabria y Argüello, 2003; Kröhling y Carignano, 2014), expuesta en cercanías a la localidad de Despeñaderos, Córdoba. Sin embargo, existen importantes diferencias de facies y probablemente de edad entre esas unidades. Cantú (1992) le asignó a la Formación Alpa Corral una edad próxima al límite Plio-Pleistoceno. Esta edad fue inferida porque se vinculó esta formación con el desarrollo del abanico aluvial producto del levantamiento principal de las Sierras Pampeanas al final del Plioceno y comienzos del Pleistoceno, siguiendo a Gordillo y Lencinas (1979).

La falta de estudios bioestratigráficos o geocronológicos de detalle ha generado la idea de la existencia de un solo levantamiento principal de las Sierras Pampeanas cercano al límite Plio-Pleistoceno $\mathrm{y}$, consecuentemente, al intento fallido de correlacionar las unidades sedimentarias neógenas y cuaternarias de los diferentes valles, aún cuando corresponden muchas veces a facies sedimentarias muy diferentes. Sin embargo, algunas investigaciones más recientes (Tauber et al., 2017) permitieron interpretar, sobre la base del registro bioestratigráfico de mamíferos fósiles, que el levantamiento de las Sierras Pampeanas Orientales fue un proceso que se produjo en etapas y, aparentemente, en forma diacrónica, al menos en lo que se refiere al inicio de la sedimentación neógena. Este diacronismo se habría producido desde los depósitos neógenos más antiguos de la parte occidental de las Sierras Pampeanas Orientales (Plioceno temprano y tardío [Edad Montehermosense-Chapadmalalense] en el Valle de San Alberto), hacia el sector oriental (Plioceno tardío [Edad Chapadmalalense] en el valle de La Cruz), coincidiendo con la dirección general de propagación de la deformación andina de la corteza terrestre, durante la subducción de bajo ángulo de la placa de Nazca (Tauber et al., 2017). Recientemente se registraron también niveles de la Formación Brochero en el valle de San Alberto, con una asociación de restos de mamíferos del Mioceno tardío (Edad Huayqueriense), marcando aún más este diacronismo (Tauber et al., 2018).

Ante la falta de un análisis integrador, el principal objetivo de este trabajo es ampliar el conocimiento bioestratigráfico de la cubierta sedimentaria del Cenozoico tardío, del sector oriental de las Sierras de Córdoba, para lograr mayor precisión en la determinación de la edad de estos depósitos, especialmente de aquellos correspondientes al inicio de la acumulación neógena, e interpretar la evolución geológica producida durante su desarrollo en el piedemonte oriental de la Sierra de los Comechingones en cercanías de la mencionada localidad de Alpa Corral, más precisamente en las cuencas de los ríos de Las Barrancas y San Bartolomé. Para ello, se plantearon las siguientes hipótesis: (1) la edad de los sedimentos neógenos más antiguos que afloran en el piedemonte oriental de la Sierra de los Comechingones, en la región de 


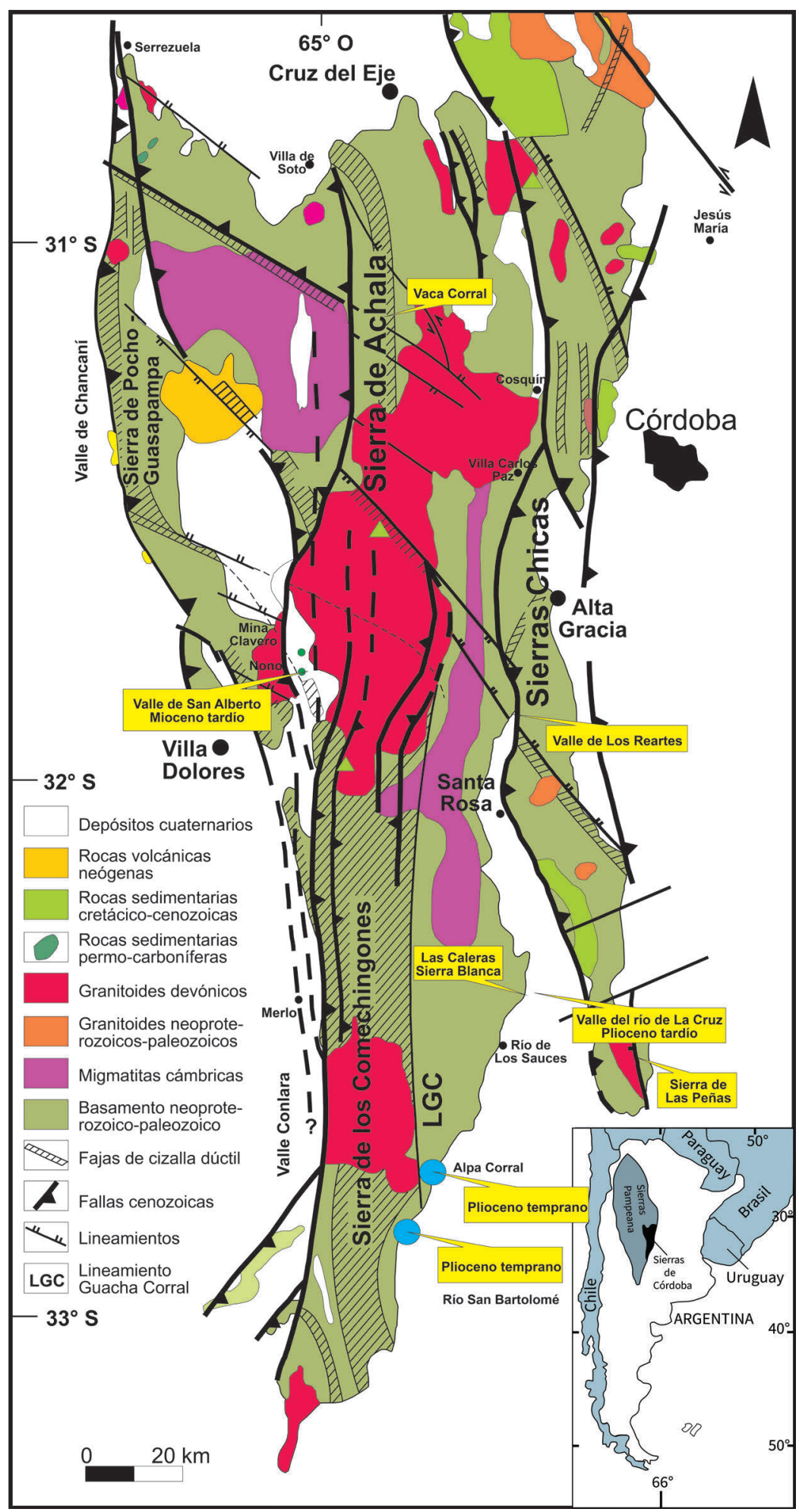

FIG. 1. Ubicación del área de estudio y posición geográfica de las columnas analizadas en los ríos de Las Barrancas (Alpa Corral) y San Bartolomé. Modificado de Martino et al. (2014). 


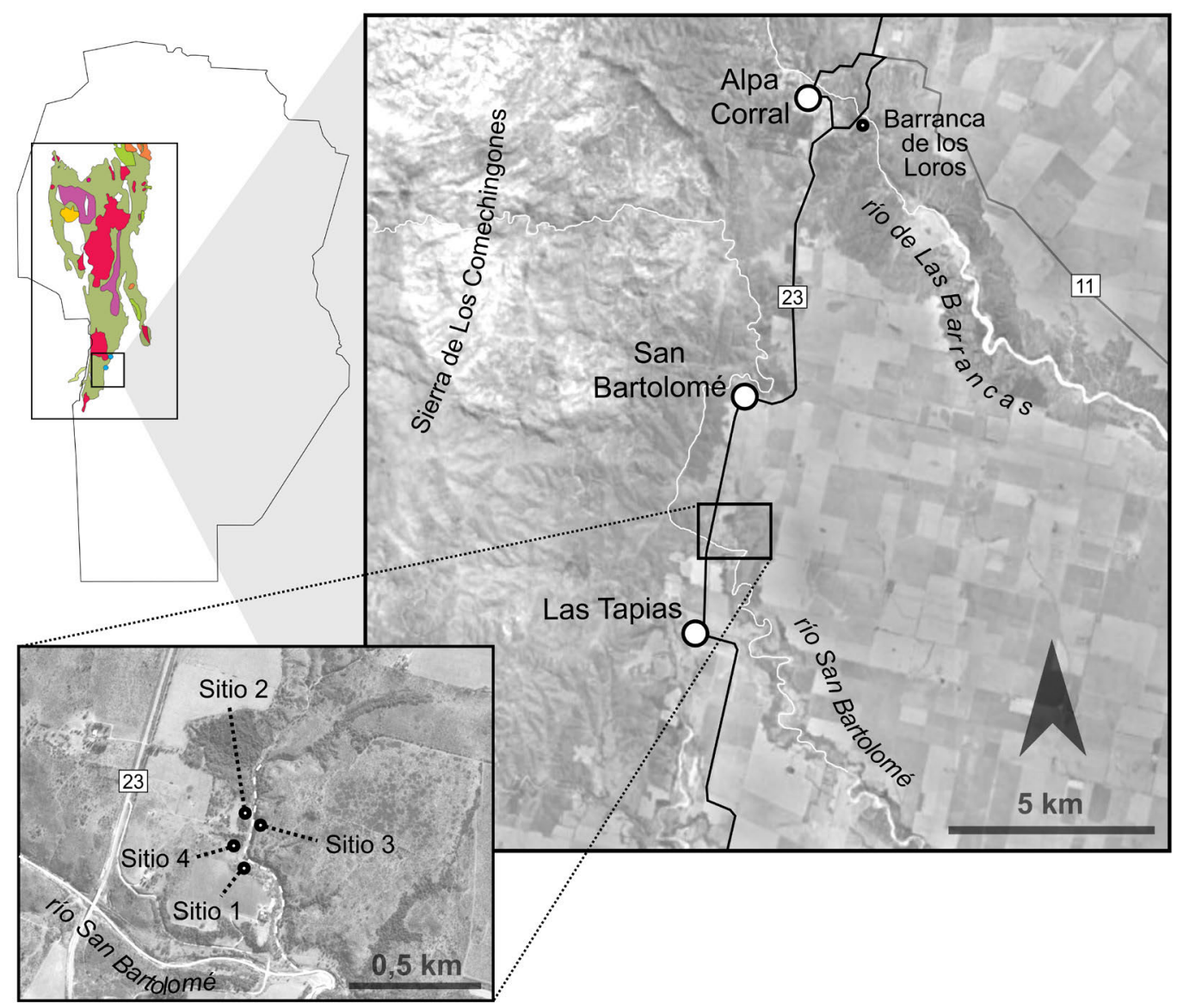

FIG. 2. Ubicación geográfica del sitio Barranca de los Loros (sobre el río de Las Barrancas) y de los nuevos sitios fosilíferos (sitios 1, 2, 3 y 4) sobre las márgenes de un afluente del río San Bartolomé.

Alpa Corral, corresponde al Plioceno temprano (Edad Montehermosense); (2) la horizontalización de la placa de Nazca produjo la formación de los grandes valles de la Provincia de San Luis y Córdoba y la posterior sedimentación en forma diacrónica durante el Mioceno tardío al oeste y Plioceno tardío al este (valle del río de La Cruz).

\subsection{Abreviaturas institucionales}

CORD-PZ: Museo de Paleontología de la Facultad de Ciencias Exactas, Físicas y Naturales de la Universidad Nacional de Córdoba, colección de paleozoología; MACN Pv: Colección Nacional de Paleovertebrados, Museo Argentino de Ciencias Naturales "Bernardino Rivadavia", Buenos Aires, Argentina.

\section{Marco geológico regional}

Las Sierras de Córdoba se encuentran en la región central del territorio continental de la República Argentina, sobre la parte occidental de la Provincia de Córdoba y forman parte del extremo suroriental de la provincia geomorfológica de las Sierras Pampeanas. Al igual que estas, se componen de un conjunto de cordones montañosos de orientación aproximadamente norte-sur que corresponden a bloques limitados por fallas de carácter inverso (Fig. 1), separados por valles tectónicos longitudinales.

Las Sierras de Córdoba están compuestas por cinco cordones mayores: Sierra Norte-Ambargasta, Sierras Chicas-Las Peñas, Sierras Grandes-Comechingones, Sierras de Pocho-Guasapampa y los valles estructurales interserranos, dentro de los cuales están incluidos los 
valles de San Alberto y del río de La Cruz (Fig. 1). Estos grandes valles de las Sierras Pampeanas de Córdoba habrían tenido un origen común producido a partir del Mioceno tardío. Esta estructuración joven ha permitido la acumulación de depósitos cenozoicos, predominantemente de materiales clásticos, en los valles interserranos, donde actualmente afloran en forma parcial en terrazas fluviales producto del desequilibrio de los niveles de base y coronados por depósitos cuaternarios (Beltramone, 2004; Astini et al., 2014; Carignano et al., 2014; Kröhling y Carignano, 2014; Krapovickas y Tauber, 2016; Krapovickas et al., 2017; Cruz et al., 2017, 2019; Tauber et al., 2017, 2019a, b).

Las unidades litoestratigráficas sedimentarias neógenas están distribuidas regionalmente y se relacionan con el levantamiento de las sierras a partir del Mioceno tardío. Desde esta etapa de estructuración, con la inversión y reactivación tectónica de antiguas estructuras, se produjo en la región serrana una fuerte deformación del antepaís, generando los sistemas aluviales o fluviales en forma diferencial y diacrónica de oeste a este. De esta manera se diferencia del piedemonte y la llanura ubicados hacia el este de las Sierras de Córdoba, donde el registro sedimentario es mucho más continuo. Los depósitos de la región montañosa, están siendo elevados junto con las sierras y forman parte de rellenos sedimentarios en desequilibrio por estar relacionadas desde el Neógeno, directamente con estructuras activas o en áreas muy próximas a ellas (Astini et al., 2014).

En los márgenes de los relieves tectónicos y valles interserranos, se depositaron estos sedimentos continentales, de origen coluvial, aluvial y fluvial, en general de color pardo o pardo rojizo y comúnmente cubiertos por unidades cuaternarias de origen aluvial, fluvial o eólico (loess y loessoides). Dentro de estas regiones pedemontanas y valles se desarrollaron abundantes calcretas, fundamentalmente en áreas próximas a los cuerpos de mármoles del basamento y paleosuelos con diferentes grados de madurez formados en llanuras de inundación, especialmente en niveles de Edad Chapadmalalense. El ejemplo más destacado se encuentra en el valle de La Cruz donde las calcretas de Edad Chapadmalense están muy desarrollados (Tauber et al., 2017) y su génesis estaría vinculada con el proceso de disolución y generación de fenómenos cársticos de la Sierra Blanca (Las Caleras) como fuente de aporte (Tauber, 2000).
La secuencia sedimentaria del sector pedemontano oriental de la Sierra de Los Comechingones (Fig. 1) está dominada por sedimentitas neógenas y cuaternarias. Estas últimas cubren todo el ambiente pedemontano y están integradas por una secuencia fundamentalmente fluvio-eólica que aumenta en potencia hacia el este vinculándose progresivamente con los sedimentos loéssicos de la llanura eólica oriental (Caniggia, 2004; Asurmendi, 2015; Tauber et al., 2017).

La localidad de Alpa Corral (Figs. 1 y 2) se ubica precisamente sobre el límite entre la vertiente oriental de la Sierra de Los Comechingones y el borde occidental del piedemonte, en el departamento Río Cuarto, provincia de Córdoba (Carignano et al., 2014: figs: 2, 4). Es una antigua bajada dislocada tectónicamente y erosionada por los afluentes del río Chocancharava (los ríos de Las Barrancas-Seco, San Bartolomé-La Invernada, Las Cañitas y Piedras Blancas) y del arroyo Santa Catalina (La Colacha, Cipión, Barranquita y Knützen). Estos cauces han erosionado profundamente sobre el terreno, de relieve ondulado muy irregular, con desniveles locales del orden general de 50-70 m. Según varios autores, los bloques que conforman el sector del piedemonte están compuestos por depósitos aluviales neógenos y cuaternarios con niveles de paleosuelos y calcretas de espesores muy variables (Cantú, 1992; Andreazzini y Degiovanni, 2011; Carignano et al., 2014). En esa región se analizaron dos afloramientos de la secuencia sedimentaria del piedemonte oriental de la mencionada sierra, principalmente de origen epiclástico del Cenozoico tardío donde se hallaron fósiles neógenos y continentales, consistentes en restos óseos de vertebrados y trazas de invertebrados.

El primer sitio paleontológico conocido en la región, donde se registraron vertebrados (mamíferos y un reptil) del Plioceno, está ubicado en la Barranca de Los Loros (3241'59,57' S y 6442'27,40" O; 796 m s.n.m.), sobre el margen derecho del río de Las Barrancas (o río Alpa Corral sensu Kröhling y Carignano, 2014), afluente del río Chocancharava (o río Cuarto) (Fig. 2). Allí se reconoció una secuencia compuesta por dos unidades litoestratigráficas separadas por una discontinuidad erosiva que tiene expresión regional (e.g., en el valle de La Cruz, Tauber et al., 2017). La unidad superior corresponde a depósitos aluviales de edad cuaternaria (Fig. 3). Por su parte, la unidad inferior tiene un espesor visible de $15 \mathrm{~m}$, está compuesta por sedimentos limo arcillosos o 




FIG. 3. Correlación estratigráfica de los diferentes niveles fosilíferos registrados en el río San Bartolomé, Barranca de Los Loros y valle del río de $\mathrm{La}$ Cruz.

limo arenosos finos de color pardo rojizos poco consolidados, en los que se observa una estructura en general masiva o estratificación paralela horizontal débilmente marcada. Algunos niveles muestran estructuras en bloques, cutanes y moteado, evidenciando un proceso pedogenético. Intercalado con estas pelitas se halla un cuerpo sedimentario con sección lenticular, base erosiva y relleno grano decreciente, desde conglomerado grueso clasto soportado hasta arcillita con estructura masiva hacia el techo. En el cuarto superior de la columna se observan dos niveles delgados y continuos de color blanquecino que tienen sus bases planas y netas, y su techo transicional compuesto por pelita que interpretamos de origen volcanoclástico producido por caída pliniana (Fig. 4A, 4F, 4G y 4H; Giannoncelli y Tauber, 1997; Astini et al., 2014; Tauber et al., 2014, 2019a).

El paleoambiente sedimentario correspondería a una llanura de inundación con generación de suelos, desarrollada bajo condiciones climáticas 


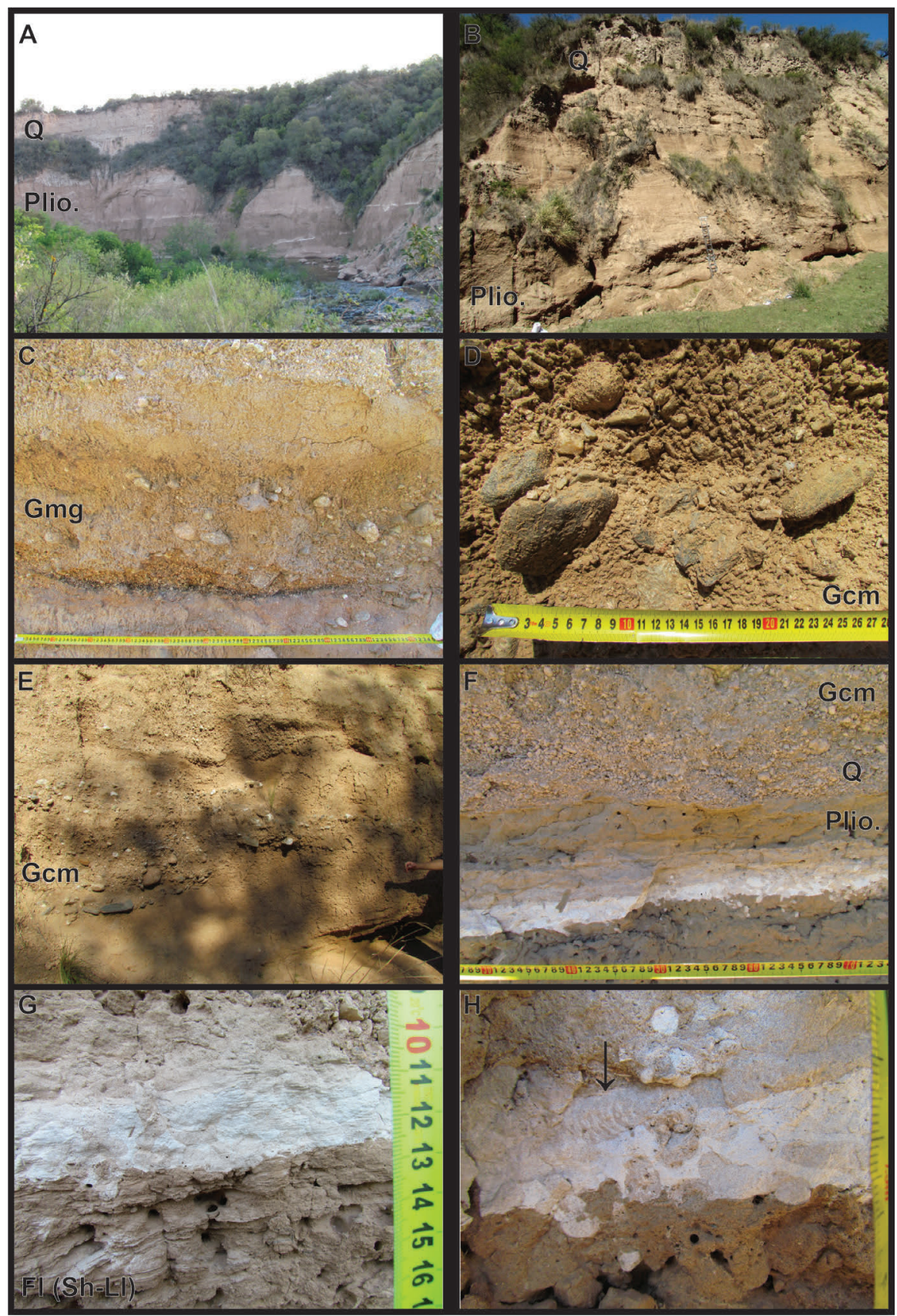

FIG. 4. Afloramientos de la secuencia sedimentaria del Plioceno (Plio.) y Cuaternario (Q) de la regíon de Alpa Corral, en el río de las Barrancas y río San Bartolomé. A. Barranca de Los Loros sobre el río de Las Barrancas; B. Barranca sobre un arroyo afluente del río San Bartolomé. C-H. Principales facies sedimentarias de las Asociaciones de facies A y B observadas en la cuenca del río San Bartolomé; C. Conglomerado grueso matriz soportado y gradación normal (Gmg); D. Conglomerado mediano a fino clasto soportado con estructura masiva con clastos imbricados $(\mathrm{Gcm})$; E. Conglomerado clastos soportado masivo $(\mathrm{Gcm})$, como relleno de un canal; F. Conglomerado mediano a fino con estructura masiva y clastos imbricados (Gcm) del Pleistoceno (Asociación de facies B) en contacto sobre niveles de la icnofacies de Scoyenia; G. Arena muy fina, limolita y arcilita poco consolidada, depósito epiclástico (pardo rojizo) y volcanoclástico (blanquecino), con laminación fina horizontal, escasas y pequeñas ondulitas, muy bioturbada [icnofacies de Scoyenia, Fl (Sh-L1)]; H. La flecha indica trazas horizontales y meniscadas determinadas como Taenidium barretti de la icnofacies de Scoyenia (Asociación de facies A). 
más cálidas y húmedas que las existentes en la actualidad, mientras que los vertebrados fósiles registrados sugieren áreas abiertas con pastizales. Esta unidad yace en discordancia sobre el basamento metamórfico, interpretándose que la sedimentación neógena del valle del río de Las Barrancas se habría originado durante el Mioceno (Fig. 3) (Giannoncelli y Tauber 1997; Astini et al., 2014; Tauber et al., 2014, 2017, 2019a).

En la base de la unidad inferior ( $5 \mathrm{~m}$ inferiores), que aflora en la Barranca de Los Loros, se registraron 6 niveles fosilíferos portadores de restos de vertebrados que permitieron interpretar tentativamente una edad pliocena temprana a tardía (Edad Montehermosense para los cuatro niveles inferiores y Chapadamalalense para el nivel superior), según los esquemas bioestratigráficos de la costa bonaerense (Giannoncelli y Tauber, 1997). Sin embargo, aún no fueron descritos ni ilustrados los materiales fósiles recolectados y es preciso realizar una revisión de esas determinaciones (Tauber et al., 2014, 2019a).

\section{Nuevos sitios fosilíferos}

El segundo afloramiento analizado incluye los nuevos sitios fosilíferos que se registran por primera vez en este trabajo (indicados como sitio 1, 2, 3 y 4 en la Fig. 2) y se encuentran ubicados en las cercanías de la localidad de Las Tapias, y en un arroyo afluente sobre el margen izquierdo del río San Bartolomé, perteneciente ambos a la cuenca del río Chocancharava ( $32^{\circ} 47^{\prime} \mathrm{S}$ y $\left.64^{\circ} 44^{\prime} \mathrm{O}\right)$ ). Allí aflora una secuencia sedimentaria en discordancia sobre el basamento metamórfico de características similares a las observadas en la Barranca de Los Loros (en las cercanías de Alpa Corrral). En ese lugar se observan tres unidades litoestratigráficas separadas las dos inferiores por una discontinuidad erosiva que, como se mencionó, tienen su expresión a nivel regional (Fig. 3; e.g., Barranca de Los Loros en Alpa Corral o en el valle de La Cruz, Tauber et al., 2017).

\section{Análisis de facies}

En el piedemonte oriental de la Sierra de los Comechingones se han registrado desde facies conglomerádicas hasta pelíticas. Las características de estas litofacies y la interpretación de los procesos de acumulación se resumen en la tabla 1. Las facies psamíticas son predominantes, aunque las facies pelíticas también son muy abundantes y en menor proporción se encuentran las facies conglomerádicas finas a gruesas, mayoritariamente matriz sostenida. Se observaron pelitas con estructuras pedogenéticas que sirvieron como niveles guías para realizar correlaciones entre las diferentes secciones estudiadas.

\subsection{Icnofacies de Scoyenia}

En el sitio 1 (Fig. 2) (32॰47’20,50” S y 64\%4 '39,04" O) se observa, en el intervalo superior de la Asociación de facies A, una capa (1 m de espesor visible aproximadamente) de arenisca fina y limolita de origen epiclástico y volcaniclástico, con laminación horizontal bien marcada, escasas y pequeñas ondulitas y profusamente bioturbado (facies Fl o Fm, Fig. 4F-H). Sobre esta facies se observan abundantes trazas de invertebrados, aunque es muy baja la icnodiversidad, alcanzando un índice de bioturbación de 4 (sensu Bann et al., 2008; MacEachern et al., 2010). Algunas de estas trazas son estructuras biogénicas horizontales, rellenadas y meniscadas, siendo notablemente más abundantes las estructuras verticales y horizontales en forma cilíndrica o de tubo a veces irregulares, probablemente de vivienda. Las trazas horizontales y meniscadas fueron determinadas como Taenidium barretti (Fig. 4H) y los tubos verticales como Skolithos icsp., siendo dos trazas típicas que permiten reconocer a la icnofacies de Scoyenia.

Interpretación: La icnofacies de Scoyenia se presenta en sedimentos arenosos a arcillosos, húmedos, en sitios de baja energía, tanto sedimentos ligeramente sumergidos que son periódicamente emergidos o sedimentos subaéreos periódicamente inundados, particularmente durante las crecientes del río (Frey et al., 1984; Frey y Pemberton, 1987; Buatois y Mángano, 1995). De este modo, la icnofacies de Scoyenia se presenta en ambientes continentales intermedios entre acuáticos, típicamente transicionales fluviopalustres. Los ambientes característicos incluyen planicies de inundación, meandros abandonados, estanques, márgenes de lagos, lagos efímeros e interdunas húmedas (Frey et al., 1984; Buatois y Mángano, 1995; Buatois et al., 2002). La parte superior de las barras y bancos del canal son también típicos sitios donde se desarrolla la icnofacies de Scoyenia, particularmente los depósitos de desborde (crevasse splays), donde es común. En el caso de la nueva localidad estudiada, debido al alto grado de 
TABLA 1. RESUMEN DE LAS LITOFACIES Y ASOCIACIONES DE FACIES IDENTIFICADAS EN EL RÍO SAN BARTOLOMÉ.

\begin{tabular}{|c|c|c|}
\hline \multicolumn{3}{|c|}{ Asociación de facies A } \\
\hline Código & Facies & Características \\
\hline Gmg & $\begin{array}{l}\text { Conglomerado grueso } \\
\text { matriz soportado y } \\
\text { gradación normal. }\end{array}$ & $\begin{array}{l}\text { Conglomerado pardo rojizo, polimíctico } \\
\text { fino a grueso con gradación normal y clastos } \\
\text { subangulosos mayoritariamente de } 8 \mathrm{~cm} \text {, pero } \\
\text { hay cantos que alcanzan los } 20 \text { a } 25 \mathrm{~cm} \text { de } \\
\text { diámetro máximo. La matriz está compuesta } \\
\text { por arena mediana a gruesa y localmente se } \\
\text { observan concentraciones de óxidos de Fe y } \\
\text { Mn. Este conglomerado incluye bioclastos } \\
\text { óseos escasamente alterados por abrasión. } \\
\text { Dirección de paleocorrientes: } 155-164^{\circ} \text {. }\end{array}$ \\
\hline $\mathrm{Gcm}$ & $\begin{array}{l}\text { Conglomerado } \\
\text { mediano a fino } \\
\text { clasto soportado con } \\
\text { estructura masiva. }\end{array}$ & $\begin{array}{l}\text { Conglomerado polimíctico mediano a } \\
\text { fino, clasto soportado con individuos } \\
\text { subredondeados a subangulosos de hasta } 10 \mathrm{~cm} \\
\text { de diámetro máximo, algunos son paraclastos. } \\
\text { La estructura es masiva a incipiente gradación } \\
\text { normal. Se observan clastos imbricados. }\end{array}$ \\
\hline St-Sp & $\begin{array}{l}\text { Arena gruesa, } \\
\text { mediana a fina con } \\
\text { estratificación cruzada } \\
\text { en artesas y horizontal } \\
\text { planar. }\end{array}$ & $\begin{array}{l}\text { Arena fina, mediana y gruesa, con guijas y } \\
\text { guijarros aislados soportados por la matriz } \\
\text { (polimícticos). } \\
\text { Estratificación planar horizontal y cruzada en } \\
\text { artesas de bajo ángulo. Clastos redondeados } \\
\text { a subredondeados. }\end{array}$ \\
\hline
\end{tabular}
a subredondeados.

Limolita, arcilita y arenisca muy fina subordinada masivas de color pardo rojizo. Se encuentran poco consolidadas y dispuestas en cuerpos tabulares. Presencia de clastos pequeños, dispersos y redondeados a subredondeados. Hay intercalaciones de cuerpos lenticulares de base cóncava y erosiva rellenos con delgados niveles basales de arena y grava muy fina subordinada. Algunos cuerpos tabulares se encuentran más endurecidos. Esta facies está intercalada con paleosuelos (facies P).

Fl (Sh-Ll) Arenisca muy fina, limolita y arcilita epiclásticas y piroclásticas con laminación horizontal y escasas ondulitas.

Arcilitas tabulares con estructuras pedogenéticas.
Arena muy fina, limolita y arcilita poco consolidada, epiclásticas (pardo rojizas) y volcanoclásticas (blanquecinas), con laminación fina horizontal, escasas y pequeñas ondulitas, muy bioturbada (icnofacies de Scoyenia).

Arcilitas tabulares de color pardo rojizo y tonalidad neutra a oscura con base gradual y techo neto. Estructuras pedogenéticas: peds en bloques, prismáticas, cutanes, barnices de arcilla, bioturbación de probable origen vegetal.

\section{Interpretación}

Flujo de detritos seudoplástico (baja resistencia, viscoso) que conforma el relleno de canales. Depósitos de lag (Miall, 2006).

Flujo de detritos seudoplástico (carga de fondo inercial, flujo turbulento), interpretado como depósitos de tamiz (sieve deposits) (Miall, 2006).

Las granulometrías y las estructuras sedimentarias permiten interpretar a este nivel como el resultado de la acreción lateral del cauce principal del río, con altos regímenes de flujo de corrientes mantiformes, lo que produce estructuras planares horizonales, que varían a un régimen de flujo moderado y genera artesas de bajo ángulo por migración de dunas con crestas sinuosas o linguoides (3D) (Miall, 2006).

Esta facies se interpreta como el producto de episodios de depositación en la llanura de inundación en canales secundarios en manto (Friend et al., 1979; Miall, 2006, 2010).

Depósitos de desborde, canales abandonados o depósitos de inundación menguantes (Miall, 2006; Frey et al., 1984; Buatois y Mángano, 1995; Buatois et al., 2002).

La litología y la presencia de estructuras posdepositacionales asociadas a procesos pedogenéticos permiten interpretar el ambiente como una llanura de inundación con el desarrollo posterior de paleosuelos (Retallack, 2001; Miall, 2006). 


\section{continuación tabla 1.}

\section{Asociación de facies B}

Código

Facies

Características

\section{Interpretación}

Grava polimíctica mediana a fina, clasto soportada con individuos subredon-deados a subangulosos de hasta $5 \mathrm{~cm}$ de diámetro máximo, algunos son paraclastos. La estructura es masiva a incipiente gradación normal.

Gh Grava fina clasto soportada, con estratificación horizontal.

Gp Grava fina guijarrosa. estratificación cruzada en artesas.

Arena mediana a gruesa con estratificación fina y laminación horizontal. con estructura masiva o laminación poco definida.
Grava fina y ocasionales clastos mayores, estructura clasto soportada, con estratificación horizontal.

Arena gruesa gravosa, pardo clara, con marcada estructura cruzada en artesas de pequeña escala (10 $\mathrm{cm}$ de espesor); presenta escasos bioclastos con signos muy incipientes de abrasión. Los clastos son subredondeados. En esta facies se registraron restos óseos de mamíferos sin evidencias de abrasión.

Arena mediana a gruesa, intercalada con niveles gravosos finos con estratificación fina y laminación horizontal. Laminación horizontal, particionada o de corriente.

Arena, fina a mediana con guijas dispersas en la matriz, de color pardo grisáceo con tonalidades claras con estructura masiva o laminación poco definida y escasa consolidación.
Flujo de detritos seudoplástico (carga de fondo inercial, flujo turbulento), interpretado como depósitos de tamiz (sieve deposits) (Miall, 2006).

Estructuras sedimentarias longitudinales, interpretadas como depósitos de lag y depósitos de tamiz (sieve deposits). La granulometría y la disposición horizontal de los sedimentos permiten interpretar una depositación bajo un flujo de alta energía en depósitos no encauzados (Miall, 2006)

Estructuras sedimentarias transversas o lingüiformes (dunas 2D), asociadas con ambientes fluviales de canales entrelazados con una alternancia de ciclos de energía alta a media y en general decreciente (Miall, 2006).

Dunas de cresta sinuosa o lingüiforme (3D). Es Interpretado como relleno de canal de baja energía. (Miall, 2006).

Flujo de estratificación laminar o planar (flujo crítico), que se interpreta como depósitos de canal. La granulometría y la disposición horizontal de los sedimentos permiten interpretar una depositación bajo un flujo de mediana a alta energía (Miall, 2006).

Depósitos de flujos de sedimentos gravitacionales (Miall, 2006).

\section{Asociación de facies C}

\begin{tabular}{|c|c|c|c|}
\hline Fm & $\begin{array}{l}\text { Limo arenoso } \\
\text { Masivo, pardo } \\
\text { amarillento. }\end{array}$ & $\begin{array}{l}\text { Limo arenosos masivos de color pardo } \\
\text { amarillento. Arreglo grano decreciente. } \\
\text { Clastos de roca dispersos, redondeados } \\
\text { a subredondeados hacia la base, que } \\
\text { aumentan considerablemente la selección } \\
\text { granulométrica hacia el techo. }\end{array}$ & $\begin{array}{l}\text { El arreglo y la estructura masiva permiten } \\
\text { interpretaruna depositación con un gran aporte } \\
\text { de un régimen eólico por la alta selección de } \\
\text { la fracción limo y la estructura masiva, que } \\
\text { obliteran una llanura aluvial, evidenciada por } \\
\text { la presencia de niveles de grava fina en la base } \\
\text { generados por encharcamientos ocasionales, } \\
\text { debidoaal desbordamiento del cauce principal } \\
\text { (Miall, 2006). }\end{array}$ \\
\hline
\end{tabular}


selección granulométrica y el abundante contenido de estructuras de corte y relleno y de origen biogénicas, nos permiten interpretar al paleoambiente como una llanura de inundación expuesta a exposición subaérea y colonización de la flora y la fauna, en un clima árido a semiárido. La estructura sugiere que el proceso sedimentario dominante fue por decantación, en capas planas de bajo régimen de flujo (Retallack, 2001; Miall, 2006). Estas hipótesis se apoyan también en la relación de esta icnofacies con depósitos de canales y paleosuelos, por lo que se interpreta que corresponden a llanuras de inundación con depósitos de desborde o meandros abandonados.

\section{Asociaciones de facies y correlación litoestra- tigráfica}

\subsection{Asociación de facies A: Gmg, Gcm, St, Sp, Fm, Fl, P}

En la base de la secuencia sedimentaria, en contacto discordante con el basamento metamórfico, se encuentran sedimentitas epiclásticas, con gradación normal, compuestas por conglomerado mediano a grueso, clasto soportado y masivo (Facies $\mathrm{Gcm}$ ) y conglomerado fino a grueso, matriz soportado con gradación normal con restos fósiles óseos de mamíferos (Facies Gmg; Fig. 4C). Además se observa arena con estructuras cruzada en artesa y planar horizontal (Facies St-Sp). Esta asociación de facies (10 m de espesor visible) tiene un color pardo rojizo, está dispuesta en cuerpos de secciones lenticulares con la base cóncava hacia arriba, muy irregular, erosiva y el techo es plano y transicional, por lo que se interpretan que constituyen el material de relleno de canales. El sentido de las paleocorrientes indicadas por la imbricación de los clastos y disposición de los restos óseos de Nopachtus cabrerai, muestra una orientación general desde el noroeste al sudeste, coincidiendo con la dirección de las estructuras de deformación frágil del basamento metamórfico, de acuerdo con los datos de Carignano et al. (2014) y del curso del río San Bartolomé, controlado tectónicamente.

Estos depósitos fluviales están intercalados con limolita, arcilita y arenisca muy fina subordinada masivas de color pardo rojizo (Facies Fm) y delgados niveles de conglomerados finos soportados por la matriz, que es limo arenosa (Facies Gm). Estas facies están dispuestas en cuerpos tabulares o con secciones lenticulares, con base cóncava hacia arriba, erosiva y techo plano y transicional. Intercalada entre estas facies, se registró una serie de niveles con mayor contenido de arcilla de color pardo rojizo y tonalidad ligeramente más oscura que la facies anterior y en los que se pudo observar la presencia de peds prismáticos, barnices y pedotúbulos de raíces de tamaño similar al de las raíces de los arbustos, por lo que se interpretó a estos cuerpos como paleosuelos muy maduros, probablemente molisoles (Facies P; Retallack, 2001).

La presencia de areniscas finas, limolitas y limolitas arcillosas laminadas con el desarrollo de una profusa bioturbación de la icnofacies de Scoyenia en materiales epiclásticos y volcanoclásticos, se interpreta como indicadora de un ambiente de baja energía, sumergido y periódicamente expuesto a la exposición subaérea, compatible con un meandro abandonado o depósitos de desborde en una llanura de inundación (Fig. 4F-H).

Para esta asociación de facies, las características litológicas e icnológicas indican un ambiente fluvial de canales asimétricos, meandriformes, con rellenos multiepisódicos y de energía media, intercalado con horizontes pelíticos fuertemente pedogenizados, generando en forma alternante y cíclica, una secuencia de paleocanales y suelos maduros. En la sección inferior de esta asociación de facies predominan los canales con un bajo valor en la relación ancho/profundidad, lo que sugiere la presencia de canales poco móviles, probablemente influenciados por la alta cohesividad del material en el cual se desarrollaron. Los suelos descriptos son más abundantes hacia el techo de esta unidad y esto parece indicar una progresiva disminución en la tasa sedimentaria. La presencia de los paleosuelos maduros, bioturbados, con estructuras prismática, evidenciando una gran traslocación de arcillas, nos estaría indicando condiciones climáticas húmedas para el Plioceno temprano en esta región de Córdoba. Correlación: Como se mencionó, esta asociación de facies se encuentra en discordancia sobre el basamento metamórfico. Esto es observable en el

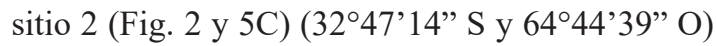
y conforma una unidad correlacionable en parte con la unidad basal expuesta en la Barranca de Los Loros (en las proximidades de Alpa Corral) y con los niveles intermedios de la Formación Brochero en su área tipo del valle de San Alberto. Por las características litológicas descriptas y la posición estratigráfica directamente sobre el basamento, esta unidad puede ser asignada a la Formación Alpa Corral 


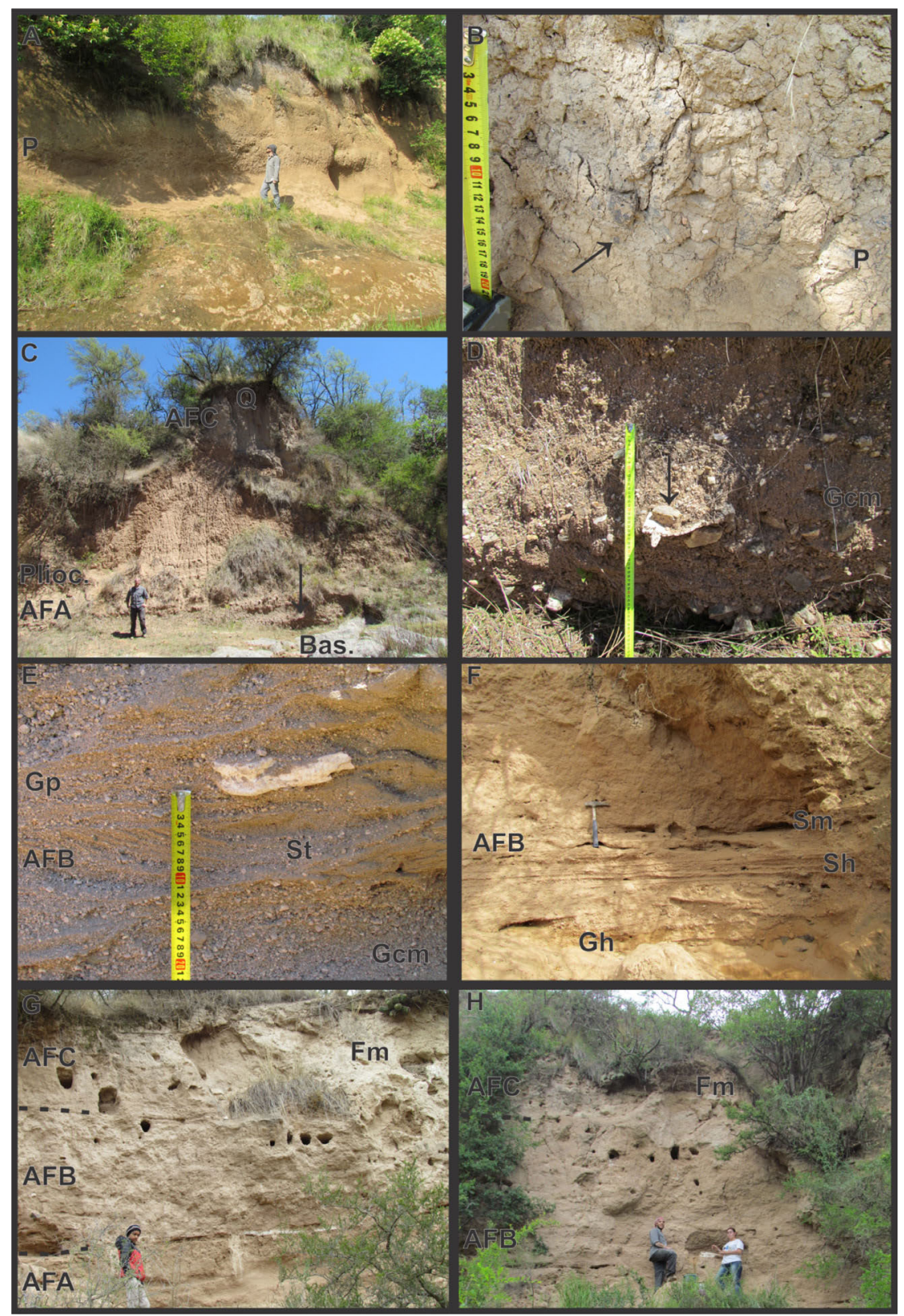

FIG. 5. Afloramientos de la secuencia sedimentaria del Plioceno (Plio.) y Cuaternario (Q) de la cuenca del río San Bartolomé, en las cercanías de la localidad de Los Talas. A. Barranca de donde se observan niveles con alto contenido de arcilla que se interpretan como horizontes Bt de un paleosuelo (P) dentro de la Asosciación de facies A; B. Horizonte Bt de un paleosuelo, donde la flecha indica la presencia de una estructura en bloques y cutanes; C. La Asociaciones de facies A dispuesta sobre el basamento metamórfico (Bas.) y la Asociación de facies C en la parte alta (la flecha indica la procedencia de los restos de cf. Trigodon gaudryi); D. Conglomerado mediano a fino clasto soportado con estructura masiva (Gcm, Asociación de facies A), fosilífero (la flecha indica la presencia de cf. Trigodon gaudryi), que forma el relleno de un canal (visible en la base de la secuencia sedimentaria que yace sobre el basamento); E. Grava fina y arena con estratificción cruzada en artesas y estratificación fina y laminación horizontal de la Asociación de facies B ( Gcm, Gp y St); F. Grava fina clasto soportada con estratificación horizontal y arena mediana a gruesa con estratificación fina, laminación horizontal o masiva de la Asociación de facies B (Gh, Sh, Sm); G. Afloramiento de la secuencia completa con las tres asociaciones de facies (A, B y C con la facies Fm); H. Asociaciones de facies B y C. Q: Cuaternario, Plio.: Plioceno, Bas.: basamento metamórfico. 
(Cantú, 1992). Sin embargo esta unidad debería ser definida con mayor precisión, considerando las indicaciones del Comité Argentino de Estratigrafía (1992) y precisando la ubicación de un estratotipo o localidad tipo y sus límites. Teniendo en cuenta la posición estratigráfica regional, las características litológicas y el contenido paleontológico, se considera que este conjunto se habría depositado durante el Plioceno temprano (Edad Montehermosense).

\subsection{Asociación de facies B: $\mathrm{Gcm}, \mathrm{Gh}, \mathrm{Gp}, \mathrm{St}, \mathrm{Sh}, \mathrm{Sm}$}

Se trata de sedimentos arenosos heterolíticos con laminación y estratificación planar horizontal, cruzada en artesas, gradación normal y masiva (facies St, Sh y Sm; Fig. 5E-F) y gravosos, polimícticos, finos, medianos y gruesos, en general grano decrecientes, algunos masivos y en cuerpos tabulares, matriz soportados (matriz arenosa) y clasto soportados, con estructuras de corte y relleno, y estratificación planar horizontal y cruzada planar de bajo ángulo (facies $\mathrm{Gcm}$, Gh y Gp; Fig. 5E-F). Los clastos: guijas, guijarros y cantos en los niveles gravosos están redondeados a subredondeados y en algunas capas más gruesas se observan clastos imbricados. Este tipo de asociación de facies en su conjunto, se asocia a ambientes fluviales de canales entrelazados con una alternancia de ciclos de energía alta a media y en general decreciente, tractivas a suspensivas, producidas por migración de dunas con crestas sinuosas o linguoides (3D) y estructuras sedimentarias transversas (dunas 2D). Esta asociación de facies se depositó sobre una disconformidad que generó un nuevo paleorrelieve, una paleosuperficie erosiva irregular que muestra evidencias de cierto grado de canalización, especialmente donde se registran las facies de gravas más gruesas en las partes basales de esta unidad.

Correlación: Esta unidad litoestratigráfica caracterizada por la "Asociación de facies B" se correlaciona litoestratigráficamente en la región con la Formación Chocancharava de edad Pleistoceno Medio a Tardío (pisos/edades Bonaerense y Lujanense; Kröhling y Carignano, 2014), y con el miembro superior de la Formación Río Primero de edad Pleistoceno Tardío. También es correlacionable con la unidad litoestratigráfica caracterizada por la "Asociación de facies C" en el valle del río de $\mathrm{La}$ Cruz y analizada por Tauber et al. (2017) y con la unidad superior que aflora en la localidad Barranca de Los Loros (Figs. 2 y 3), sobre el margen derecho del río de Las Barrancas (Giannoncelli y Tauber, 1997; Tauber et al., 2014, 2019a).

\subsection{Asociación de facies C: Fm}

Está compuesta predominantemente por sedimentos limo arenoso masivo de color pardo amarillento y tonalidades variables, en los cuales se observa un arreglo grano decreciente (Facies Fm; Fig. 5G-H). En la base de los perfiles que se encuentran próximos al río San Bartolomé, en las cercanías de la localidad de Las Tapias, se observa la presencia de pequeños clastos dispersos, de rocas del basamento metamórfico y de calcreta, redondeados a subredondeados. En ocasiones se observan intercalaciones de pequeñas láminas de gravas polimícticas finas a medias, matriz soportada y clasto soportadas. Estas intercalaciones se interpretan como el producto del encharcamiento en la llanura de inundación por ocasionales desbordamiento del cauce principal en un ambiente de depositación fluvial-aluvial que fue obliterado por un régimen eólico, dada la alta selección granulométrica observada hacia el techo de la secuencia. Sobre esta unidad se desarrollo el suelo actualmente productivo de la región.

Correlación: Esta asociación de facies se depositó sobre la anterior en aparente conformidad o paraconformidad; es correlacionable con la Formación La Invernada, ampliamente distribuida en la región de estudio y en el valle del río La Cruz y con la Formación Vaca Corral, distribuida en las pampas de altura, por sus características litológicas, relaciones estratigráficas, contenido paleontológico y datos geocronológicos. Esta formación se habría depositado durante el Pleistoceno Tardío-Holoceno Temprano (Piso/Edad Lujanense superior, Cantú, 1992; Combina y Sánchez, 2003; Cruz et al., 2010; Cruz, 2013; Kröhling y Carignano, 2014; Tauber et al., 2017), en la planicie fluvio-eólica.

\subsection{Sistemática paleontológica}

Magnorden XENARTHRA Cope, 1889 Orden CINGULATA Illiger, 1811

Suborden GLYPTODONTIA Ameghino, 1889 Superfamilia GLYPTODONTOIDEA Gray, 1869

Familia GLYPTODONTIDAE Gray, 1869

Género Nopachtus Ameghino, 1888

Nopachtus cabrerai Zamorano et al., 2011

Fig. 6A-E 


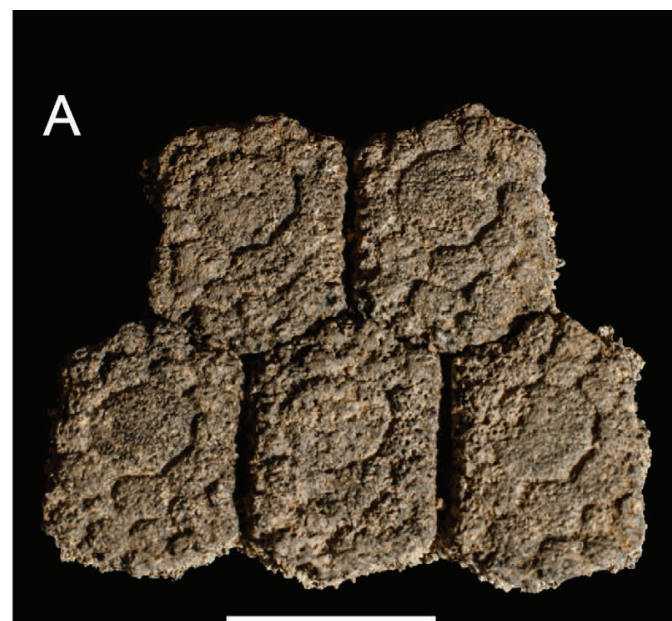

\section{B}

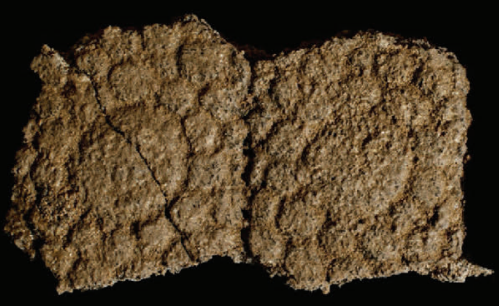

\section{$3 \mathrm{~cm}$}

C

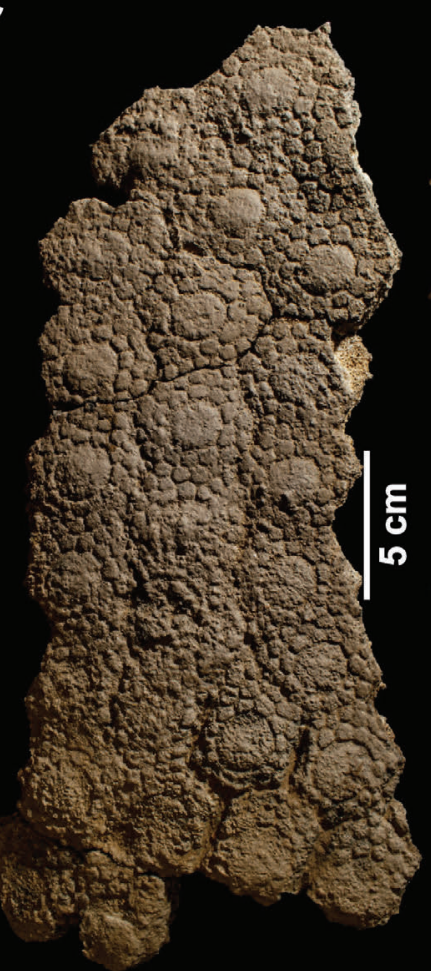

D

\section{$3 \mathrm{~cm}$}

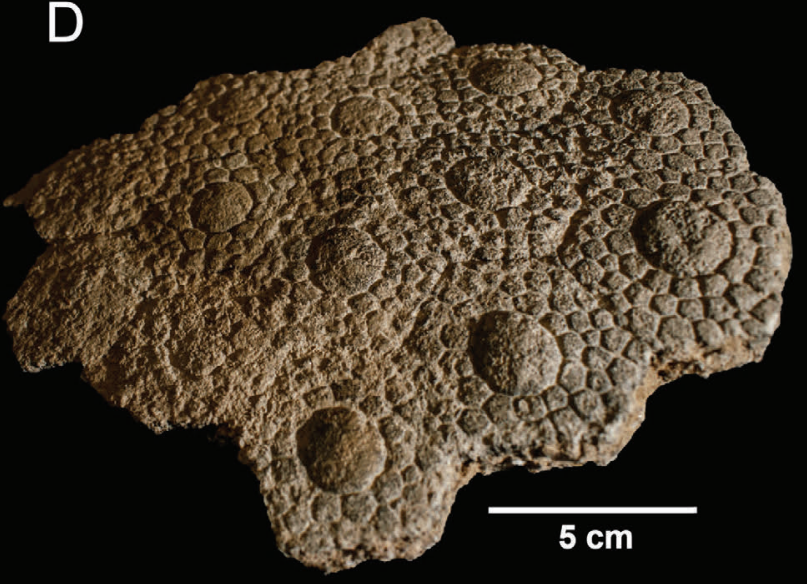

E

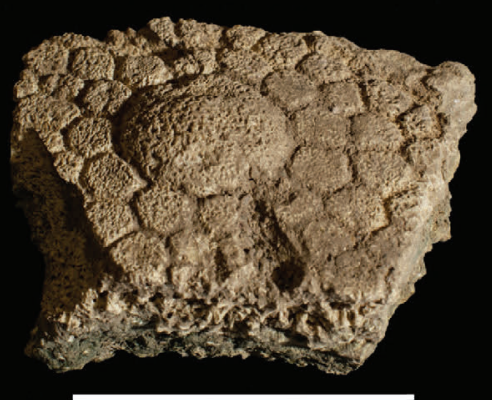

$5 \mathrm{~cm}$

FIG. 6. Nopachtus cabrerai (CORD-PZ 4573): A-B. Placas de la región anterior del caparazón dorsal; C. Placas de la región media del caparazón dorsal; D. Fragmento posterior del caparazón dorsal que incluye dos osteodermos del borde; E. Placa aislada (CORD-PZ 4574-1) de la región posterior del caparazón dorsal, donde se observa la convexidad de la figura central. 
Material fósil. Dos fragmentos de la región posterior del caparazón dorsal compuestos por más de 50 osteodermos cada uno y gran parte de uno de los coxales (CORD-PZ 4572-1/2). Un fragmento de la región dorsal anterior del caparazón, compuesto por 10 osteodermos (CORD-PZ 4573) y dos placas aisladas (CORD-PZ 4574-1/2) de la región posterior del caparazón dorsal, que podrían pertenecer todos al mismo espécimen (ver comentario más adelante). Fragmento compuesto por dos placas del caparazón dorsal (CORD-PZ 4410).

Procedencia geográfica y estratigráfica. E1 material CORD-PZ 4572-1/2 procede de la unidad estratigráfica inferior (Asociación de facies A) y particularmente de las facies Gmg y Gcm, que compone un depósito de relleno de canal, situado al pie de una barranca sobre el margen izquierdo de un arroyo afluente del río San Bartolomé (3247’15” S y 6444'38" O, elevación 747 m s.n.m., Fig. 2). Los fósiles CORD-PZ 4573 y CORD-PZ 4574-1/2 proceden de la misma unidad estratigráfica inferior (Facies St) y de un sitio ubicado entre 110 y $120 \mathrm{~m}$ de CORD-PZ 4572-1/2 (ver comentario). CORD-PZ 4410 procede de la Barranca de Los Loros (Figs. 2 y 3; Giannoncelli y Tauber, 1997: nivel fosilífero 1).

Distribución geográfica y estratigráfica. El hipodigma de esta especie está compuesto solamente por el holotipo (MACN Pv 2670), el cual procede de la Formación Monte Hermoso (Piso/Edad Montehermosense, Plioceno temprano) de la localidad Farola Monte Hermoso (Buenos Aires) (Zamorano et al., 2011, 2015; Zamorano, 2012a, 2012b; Tomassini et al., $2013 \mathrm{a}$;).

Comentario. La determinación taxonómica de este material fósil se realizó siguiendo los criterios resumidos por Zamorano et al. (2011, 2015, 2016, 2017). Se asigna a Nopachtus cabrerai por la presencia de osteodermos con una figura central rodeada por una o dos hileras de figuras periféricas poligonales. La primera de las hileras tiene entre 10 y 12 figuritas periféricas, mientras que la hilera más marginal presenta hasta 21 figuritas periféricas poligonales, principalmente pentagonales y en menor proporción hexagonales. En la región anterior los osteodermos tienen solamente una hilera completa de figuras periféricas, en la parte central del caparazón tienen dos y hacia la parte posterior tiende a tener una tercera hilera siempre incompleta. La figura central de la mayoría de los osteodermos es plana y solamente en la parte posterior de la coraza las figuras centrales son más elevadas que las periféricas y suavemente convexas.

La convexidad de las figuras centrales y la morfología y número de figuras periféricas se observan con gran dificultad en muchos osteodermos debido al grado de abrasión que sufireron. Esto se evidencia por el tejido poroso que quedó expuesto en la superficie externa de numerosas placas. Además, los fragmentos de caparazón dorsal de mayor tamaño fueron hallados en un relleno de canal y en un conglomerado grueso a mediano matriz soportado y gradación normal (facies Gmg) y conglomerado mediano a fino clasto soportado con estructura masiva (facies $\mathrm{Gcm}$ ), que denotan una alta energía del ambiente de depositación. La presencia de los osteodermos en esta facies sedimentaria también produjo un elevado grado de atrición de la superficie externa de estas placas y sus figuras, especialmente en las figuritas perfiéricas.

Los restos fósiles que se determinaron aquí como Nopachtus cabrerai (CORD-PZ 4572-1/2, 4573 y 4574-1/2), podrían corresponder todos al mismo espécimen ya que se hallaron en facies de relleno de canales, a una distancia de 150-160 $\mathrm{m}$ y alineados con una orientación de $155^{\circ}-164^{\circ}$, coincidiendo con las paleocorrientes inferidas a partir de la imbricación de los clastos y otras estructuras sedimentarias asociadas.

\section{Orden PROBOSCIDEA Illiger, 1811. Superfamilia ELEPHANTOIDEA Gray, 1821. Familia GOMPHOTHERIIDAE Hay, 1922. Género Notiomastodon Cabrera, 1929. Notiomastodon platensis Ameghino, 1888}

\section{Fig. 7D-E}

Material fósil. Fragmento proximal de incisivo superior (CORD-PZ 4571).

Procedencia geográfica y estratigráfica. El material procede de la unidad estratigráfica intermedia (Asociación de facies B) y de la facies Sm, interpretados como un depósito aluvial, en la parte media de una barranca sobre el margen derecho de un arroyo afluente del río San Bartolomé (3247'19,7” S y $64^{\circ} 44^{\prime} 38,1^{\prime \prime}$ O) (Fig. 2, sitio 4 y Fig. 5H).

Distribución geográfica y estratigráfica. El primer registro de un proboscideo en América del Sur proviene del Pleistoceno más antiguo de afloramientos de la localidad de Uquía en Argentina (López et al., 2001). Sin embargo este registro no 


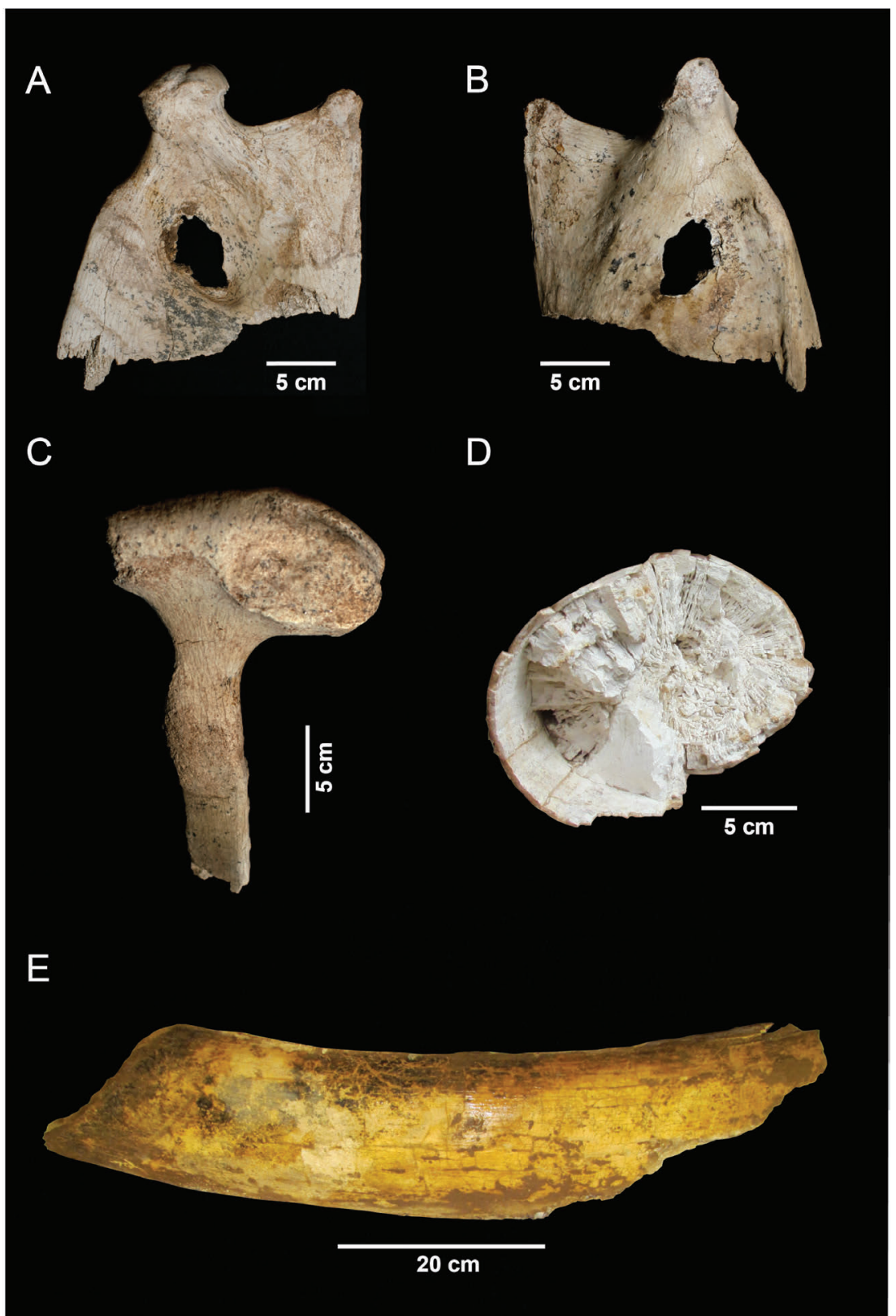

FIG. 7. cf. Trigodon gaudryi Ameghino, 1882 (CORD-PZ 4575): A. Rama ascendente del dentario izquierdo en vista interna; B. En vista externa; C. En vista posterior; Notiomastodon platensis (CORD-PZ 4571): D. Fragmento de incisivo superior en sección transversal; E. En vista lateral.

se puede atribuir con confianza a ninguna de las especies sudamericanas y resulta algo dudoso para algunos autores. El registro más antiguo conocido de Notiomastodon platensis es del Ensenadense de Argentina (Soibelzon, 2008). Esta especie tuvo un registro continuo desde el Pleistoceno Temprano hasta el Holoceno Temprano en Brasil (11 $\pm 6 \mathrm{ka}$; Dantas et al., 2013; Mothé et al., 2017). Por su parte, el registro más moderno datado en Argentina corresponde al Pleistoceno Tardío de Santa Clara del Mar, provincia de Buenos Aires $(17,880 \pm 60 \mathrm{ka}$; Alberdi y Prado, 2008; Prado et al., 2015). 
Comentario. De acuerdo con Mothé y Avilla (2015) y Mothé et al. (2017) este incisivo superior se determina como Notiomastodon platensis por su gran robustez, ligera curvatura, sección transversal ovalada y por no estar retorcido, a diferencia de lo que ocurre en Cuvieronius hyodon. Además, el esmalte está presente en una capa muy delgada cubriendo toda la periferia de este diente.

\section{Orden NOTOUNGULATA Roth, 1903 Suborden TOXODONTIA Owen, 1853 Familia TOXODONTIDAE Gervais, 1847 Subfamilia HAPLODONTHERIINAE Kraglievich, 1934 \\ Género cf. Trigodon Ameghino, 1882 cf. Trigodon gaudryi Ameghino, 1882}

Fig. 7A-C

Material fósil. Rama ascendente izquierda, la cual conserva el cóndilo mandibular y la apófisis coronoides (CORD-PZ 4575).

Procedencia geográfica y estratigráfica. El material procede de la unidad estratigráfica inferior (Asociación de facies A), de las facies Gcm y Gmg, que compone un depósito de relleno de un canal depositado sobre el basamento metamórfico, situado al pie de una barranca sobre el margen derecho de un arroyo afluente del río San Bartolomé (3247' 4" S y 6444’39”'O) (Fig. 2 y 5C).

Distribución geográfica y estratigráfica. El género Trigodon en Argentina está representado por la especie tipo T. gaudryi Ameghino, 1882 y T. minor Rovereto, 1914 (Deschamps y Tomassini, 2016), registradas ambas en la Formación Monte Hermoso. La primera fue propuesta como fósil guía para definir la biozona de Trigodon gaudryi, como base bioestratigráfica para proponer el Piso/Edad Montehermosense (Cione y Tonni, 1995a, b, c, 2005).

Comentario. El material estudiado se atribuye a cf. Trigodon gaudryi por los siguientes caracteres: 1) la apófisis coronoides es baja, aproximadamente de la misma altura que el cóndilo mandibular; 2) presenta un ángulo medianamente bien definido sobre el margen posterior de la rama ascendente, debajo y próximo al cóndilo mandibular, como sucede en otros toxodontidos; 3) el cóndilo mandibular es proporcionalmente muy grande con respecto a la apófisis coronoides y a toda la rama ascendente del dentario; esta característica es mucho más marcada en comparación con otros toxodóntidos; 4) la forma del cóndilo mandibular es aproximadamente cilíndrico y tiene su carilla articular para la cavidad glenoidea mucho más extendida hacia el lado interno del cóndilo en relación con la parte externa y proyectándose hacia atrás considerablemente (Fig. 7C); 5) borde posterior de la rama ascendente muy gruesa, delimitando una profunda fosa para la musculatura interna. Se atribuye el material estudiado a Trigodon gaudryi por su gran tamaño, diferenciándose notablemente de Trigodon minor, siendo esta última una especie dudosa de menor tamaño.

\section{Discusión}

\subsection{Correlaciones y edad de las unidades sedimentarias}

Las asociaciones de facies y las especies fósiles registradas en la nueva localidad paleontológica estudiada en la cuenca del río San Bartolomé, sobre el piedemonte oriental de la Sierra de Los Comechingones, indican claramente la presencia de tres unidades estratigráficas de edades bien diferenciables (Figs. 7 y 8). La unidad inferior, caracterizada por la Asociación de facies A, yace en no concordancia sobre el basamento metamórfico y es de edad neógena. La unidad intermedia, caracterizada por la Asociación de facies $\mathrm{B}$, es de edad pleistocena, mientras que la unidad superior, caracterizada por la Asociación de facies C, probablemente es de edad pleistocena tardía-holocena temprana. Las dos primeras están separadas por una disconformidad, una superficie erosiva ampliamente representada en la región serrana de Córdoba. Las asociaciones de facies $\mathrm{B}$ y $\mathrm{C}$ se hallan separadas por una aparente conformidad o paraconformidad, igualmente reconocible regionalmente y en el valle del río de La Cruz (Tauber et al., 2017).

El nuevo registro del glyptodóntido Nopachtus cabrerai en la cuenca del río San Bartolomé (Sitio 3, Figs. 2 y 3) permite correlacionar a la Asociación de facies A de este trabajo con la Formación Monte Hermoso de la provincia de Buenos Aires y asignarla a priori al Plioceno temprano (Piso/Edad Montehermosense), confirmando la presencia de depósitos de esta edad en el piedemonte oriental de la Sierra de los Comechingones, como se había interpretado para la unidad sedimentaria neógena basal de la Barranca de Los Loros, en las cercanías de Alpa Corral, de acuerdo con las interpretaciones 


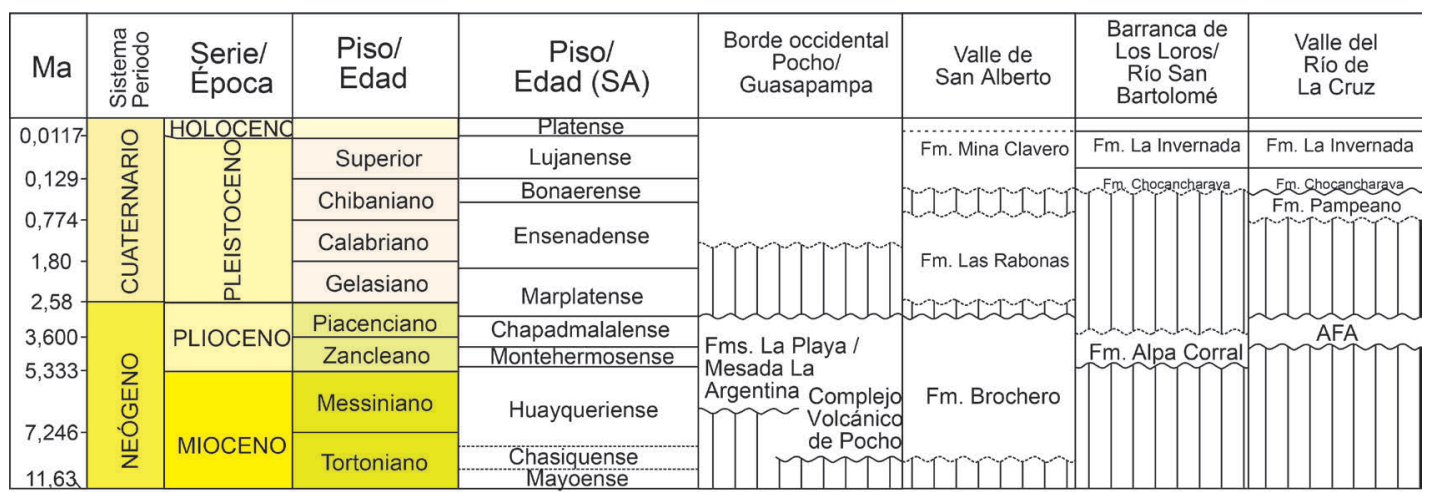

FIG. 8. Correlaciones entre formaciones de diferentes unidades geomorfológicas de la provincia de Córdoba, entre el Neógeno y Cuaternario. SA: Sudamérica; AFA: Asociación de facies A.

realizadas previamente (Giannoncelli y Tauber, 1997; Tauber et al., 2014). El material determinado como cf. Trigodon gaudryi, en el caso de confirmarse la presencia de esta especie en estos depósitos, también permitiría asignar a esta unidad al Plioceno temprano (Piso/Edad Montehermosense), ya que se trata de una especie que fue registrada en la Formación Monte Hermoso y propuesta como guía (biozona de Trigodon gaudryi) y base bioestratigráfica para el Piso/Edad Montehermosense (sensu Cione y Tonni, 1995 a, b, c, 2005). Más tarde Tomassini (2012) y Tomassini et al. (2013 a) propusieron una redefinición del Piso/Edad Montehermosense empleando para eso a la biozona de Eumysops laeviplicatus (Rodentia, Echimyidae) como base bioestratigráfica de este piso, quedando el registro de Trigodon gaudryi restringido a la sección inferior de este piso (Cione et al., 2015).

Por tal motivo, debido a la proximidad geográfica de los depósitos fosilíferos aquí estudiados de la cuenca del río San Bartolomé y de la Barranca de los Loros y que yacen en contacto sedimentario sobre el basamento metamórfico precámbrico (e.g., $32^{\circ} 47^{\prime} 14^{\prime \prime}$ S y 644' $39^{\prime \prime}$ O), se interpreta que el inicio de la sedimentación en esta región de la vertiente oriental de la Sierra de los Comechingones, entre la localidad de Alpa Corral y el río San Bartolomé, se produjo durante el Plioceno temprano (Piso/Edad Montehermosense).

Si bien la edad de la Zona de Eumysops laeviplicatus aun no se pudo determinar con precisión, Tomassini et al. (2013a) tuvieron en cuenta las dataciones numéricas logradas en otras localidades diferentes a la localidad tipo $(5,28 \pm 0,04 \mathrm{Ma}$, en la Cantera Vialidad, $3,27 \pm 0,08 \mathrm{Ma}$, en Chapadmalal) e interpretaron que esta abarcaría un lapso breve incluido dentro de un rango temporal mayor, cuyos límites serían $<5,28 \mathrm{Ma}$ y 4,5/5,0 Ma aproximadamente. De ser así, el Piso/ Edad Montehermosense no se extendería hasta el Mioceno tardío ( $c a$. 6,8/7,0 Ma) como lo sugirieron otros autores (e.g., Cione y Tonni, 2005; Reguero y Candela, 2010). De acuerdo con Tomassini et al. (2013b) la asociación de facies de la localidad Farola de Monte Hermoso, donde se encuentra el estratotipo de la formación homónima, representaría una "ventana temporal" dentro del Piso/Edad Montehermosense, cuya resolución temporal máxima sería de $10^{5}$ años.

En la Asociación de facies B de la secuencia sedimentaria del río San Bartolomé se ha documentado la presencia del proboscídeo Notiomastodon platensis, cuyo registro más antiguo de esta especie es del Ensenadense de Argentina (Soibelzon, 2008). Este Gomphotheriidae tuvo un registro continuo desde el Pleistoceno Temprano hasta el Holoceno Temprano en Brasil (11 $\pm 6 \mathrm{ka}$; Dantas et al., 2013; Mothé et al., 2017). Sin embargo, el hallazgo más moderno con dataciones en Argentina corresponde al Pleistoceno Tardío de Santa Clara del Mar, provincia de Buenos Aires (17,880 460 ka; Alberdi y Prado, 2008; Prado et al., 2015). En la provincia de Córdoba, $N$. platensis ha sido hallado en diferentes localidades de la llanura y piedemonte oriental de las Sierras Pampeanas, en depósitos aluviales y fundamentalmente fluviales, correspondientes a la Formación Río Primero de la ciudad de Despeñaderos, Miramar (sobre la costa del Mar de Ansenuza), río Xanaes (en las proximidades de la ciudad de Río Segundo), valle de Los Reartes, y en el arroyo Tegua (Castellanos, 1922; Montes, 1960, Rey Ocampo, 2015; Cruz et al., 2019). 
El taxón también fue registrado en un área más elevada de las Sierras Pampeanas, en la pampa de altura Vaca Corral (o Majada de Santiago), donde se encuentra la localidad tipo de la Formación Vaca Corral a 1.600 m s.n.m. Este es el único sitio en Córdoba con restos de $N$. platensis y dataciones por OSL (Optically stimulated luminescence) indican una edad Pleistoceno Tardío y un rango temporal entre los $37.095 \pm 2.020$ y $14.040 \pm 785$ años AP (Tauber y Goya, 2006; Krapovickas, 2014; Krapovickas y Tauber, 2016; Krapovickas et al., 2017). De acuerdo con las interpretaciones realizadas a nivel regional, la Asociación de facies $B$ es litoestratigráficamente correlacionable con la Asociación de facies $\mathrm{C}$ estudiada en el valle del río La Cruz (Fig. 1; Tauber et al., 2017) y con la Formación Chocancharava (Pleistoceno MedioTardío) de origen fluvial, aunque representaría depósitos aluviales proximales.

En la Asociación de facies $\mathrm{C}$ no se han registrado fósiles en la región de Alpa Corral, dificultando la determinación de la antigüedad de la misma. Sin embargo, como se mencionó anteriormente, esta asociación de facies es correlacionable con la Formación La Invernada, ampliamente distribuida en la región y en el valle del río La Cruz (Fig. 1), por sus características litológicas, relaciones estratigráficas y datos geocronológicos. La Formación La Invernada se habría depositado durante el Pleistoceno TardíoHoloceno Temprano (Edad Lujanense superior) (Cantú, 1992; Combina y Sánchez, 2003; Cruz et al., 2010; Cruz, 2013; Kröhling y Carignano, 2014; Tauber et al., 2017), en la planicie fluvio-eólica. La asociación de facies $\mathrm{C}$ también es correlacionable con la facies 4 de la Formación Vaca Corral, que se habría depositado durante el Pleistoceno Tardío-Holoceno Temprano y el rango temporal estimado mediante las dataciones de OSL y AMS (Accelerator mass spectrometry) realizadas sería entre los $14,040 \pm 785$ - 9,181 cal. años AP, respectivamente (Krapovickas y Tauber, 2016).

\subsection{Significado de los nuevos registros en el contexto geológico y biocronológico regional}

La edad de los depósitos sedimentarios neógenos del valle de San Alberto, al oeste de la sierra de Córdoba, donde se definió por primera vez la Formación Brochero u "Horizonte Brocherense" (Castellanos, 1942; Sayago, 1978), aún es un tema de debate. En general se asignó a la edades Montehermosense y Chapadmalalense, extendiéndose probablemente hasta la Edad Marplatense y Subedad Vorohuense (Cruz et al., 2017). Recientemente se comunicó el hallazgo de los mamíferos Macrochorobates scalabrinii y Hemihegetotherium achataleptum, entre otros, del Mioceno tardío (Edad Huayqueriense), procedentes de un nivel basal de la Formación Brochero (Tauber et al., 2018, 2019c). Esto indicaría que la sedimentación neógena en el valle de San Alberto habría comenzado, al menos, durante el Mioceno tardío (Edad Huayqueriense), siendo estos datos más acordes con las dataciones de los primeros eventos del vulcanismo del departamento Pocho $(7,9 \pm 0,6 \mathrm{Ma}$

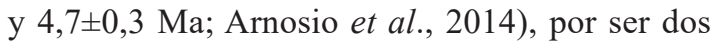
procesos geológicos que se consideran genética y geocronológicamente vinculados.

Por su parte, según los datos disponibles, y de acuerdo con el registro paleontológico, la sedimentación neógena en la vertiente oriental de las Sierras de Córdoba habría comenzado durante el Plioceno temprano (Edad Montehermosense) en el valle del río de Las Barrancas, en las proximidades de Alpa Corral (Giannoncelli y Tauber, 1997). A esto se suma el registro de la nueva localidad estudiada en la cuenca del río San Bartolomé (Fig. 2), en las proximidades de la localidad de Los Talas, donde la presencia de Nopachtus cabrerai y cf. Trigodon gaudryi también indican que la secuencia sedimentaria neógena habría comenzado a depositarse durante el Plioceno temprano (Edad Montehermosense). Estas dos localidades de la Barranca de Los Loros y del río San Bartolomé (Fig. 1) se encuentran en el tramo más austral del Lineamiento de Guacha Corral (Astini et al., 2014: Fig. 1; Martino et al., 2014: Fig. 3), en una posición más oriental respecto del valle de San Alberto y más occidental respecto del valle del río de La Cruz (Fig. 1). En este último, situado entre 40 y $60 \mathrm{~km}$ en línea recta hacia el noreste (aproximadamente en dirección $\mathrm{N} 25^{\circ}$ ) de la nueva localidad del río San Bartolomé y sobre el piedemonte oriental de la Sierra de los Comechingones, la sedimentación habría comenzado durante el Plioceno tardío (Edad Chapadmalalense) (Tauber et al., 2017).

En síntesis, los nuevos hallazgos analizados, permiten verificar la hipótesis sobre el diacronismo de la sedimentación neógena y el origen de los depocentros generados en cada valle desde el oeste hacia el este. 


\subsection{Fragmentación paleoambiental}

En estos valles y piedemonte oriental de las Sierras de Córdoba los sedimentos neógenos tienen texturas predominantemente finas o muy finas, principalmente limolitas y arcilitas, con el desarrollo de paleosuelos intercalados, en especial los niveles estratigráficos más altos y distales, mayoritariamente del Plioceno tardío (Edad Chapadmalalense). Las facies de texturas más gruesas se encuentran restringidos a algunos escasos sitios ubicados en los frentes activos de cada cordón serrano, donde se observan depósitos aluviales proximales, psefíticos (brechas o cenoglomerados), por ejemplo en la traza de la escarpa del Sistema de Fallas de las Sierras Chicas, especialmente en la zona de la ciudad de Santa Rosa de Calamuchita (Fig. 1), en exposiciones artificiales, donde el basamento cristalino yace tectónicamente sobre depósitos sedimentarios asignados al Plioceno o Plio-Pleistoceno (Costa y Vita Finzi, 1996; Simpson et al., 2001; Costa et al., 2001, 2014; Richardson, 2011; Martino et al., 2012; Sagripanti et al., 2012; Richardson et al., 2013; Tauber et al., 2019 a).

Otra cracterística general que parecen compartir los depósitos neógenos de los diferentes valles y piedemontes analizados, son los tipos de ambientes sedimentarios. Los sedimentos neógenos del valle de San Alberto se acumularon en un ambiente fluvial de tipo meandriforme (Cruz et al., 2017). Del mismo modo, el paleoambiente sedimentario interpretado para los depósitos neógenos de la región entre las localidades de Alpa Corral y la cuenca del río San Bartolomé (Fig. 2), en las proximidades de la localidad de Los Talas, corresponde a cuerpos sedimentarios originados en canales asimétricos, meandriformes, encauzados con llanuras de inudación y depósitos de desborde, meandros abandonados y paleosuelos asociados. Los sedimentos neógenos del valle del río de La Cruz, fueron interpretados igualmente como indicadores de paleoambientes similares, de sistemas de canales asimétricos, amalgamados, con llanuras de inundación y abundante desarrollo de paleosuelos maduros, especialmente en la parte más alta de la unidad de Edad Chapadmalalense, donde se generaron complejos pedogenéticos muy desarrollados en varios sectores (e.g. en los afloramientos del Río de La Cruz, Tauber et al., 2017: LC 1 y LC 2).

Este amplio predominio de facies finas a medianas en los depósitos donde se pudo demostrar la edad neógena de los mismos mediante el registro paleontológico, la presencia de canales meandriformes y el desarrollo de suelos muy maduros y complejos pedogenéticos, sugiere que el paleorrelieve generado en la primera etapa de deformación de la corteza fue bajo a moderado. Esta hipótesis es compatible con la interpretación sobre los paleoambientes generados, los que habrían sido similares en los diferentes valles y áreas pedemontanas analizadas; es decir, que los depósitos se formaron en canales meandriformes con llanuras de inundación y donde se desarrolló profusamente la pedogénesis, más que la morfogénesis. Además, el desarrollo de estos procesos pedogenéticos indican un alto grado estabilidad tectónica, especialmente durante el Plioceno tardío (Edad Chapadmalalense), tal como fue señalado previamente, por ejemplo en el valle del río de $\mathrm{La}$ Cruz o en la Formación Brochero, en el valle de San Alberto (Cruz et al., 2017; Tauber et al., 2017, 2019 a). Este período de estabilidad estaría representado también por la formación de una costra calcárea en el techo del relleno clástico del yacimiento cárstico de Las Caleras (Tauber, 2000: sitio 2; Tauber et al., 2017, 2019a).

Posteriormente se produjo una nueva etapa de levantamiento tectónico y un nuevo cambio del nivel de base en la región comprendida entre la cuenca del río San Bartolomé y la Barranca de Los Loros evidenciada por una disconformidad representada por una paleosuperficie erosiva irregular que separa los depósitos neógenos (Asociación de facies A) de los depósitos pleistocenos (Asociación de facies B) (Fig. 3). Este movimiento tectónico producido entre el Plioceno tardío y el Pleistoceno coincide, en líneas generales, con interpretaciones previas realizadas en el valle de San Alberto (Kraemer et al., 1993), Sierra Blanca (Tauber, 2000), valle del río de La Cruz (Tauber et al., 2017) y con dudas en la falla de Santa Rosa perteneciente al Sistema de Fallas de las Sierras Chicas (Martino et al., 2014). Otra importante reactivación ocurrió durante el Pleistoceno Temprano a Medio (entre el Ensenadense-Bonaerense), produciendo un nuevo cambio del nivel de base y generó una nueva disconformidad muy pronunciada que se registra a nivel regional (Tauber et al., 2017). Los efectos de estos movimientos quedaron perfectamente registrados, por ejemplo, en la Falla de Nono (Kraemer et al., 1993). Estos levantamientos, especialmente el del límite Plio-Pleistoceno, habrían generado un paleorrelieve de magnitud considerablemente mayor con respecto a los del Mioceno tardío. 
Consecuentemente, se interpreta que durante la primera etapa de formación de los depocentros neógenos, los factores ambientales relacionados con el gradiente de altitud, no habrían incidido de una manera tan acentuada como sí pudo haber ocurrido en las etapas posteriores del levantamiento de los cordones montañosos, por ejemplo, a partir del límite entre el Plioceno tardío y Pleistoceno Temprano. Estos factores son: (1) las diferencias de altura y el aumento de las pendientes y consecuentemente la velocidad de escurrimiento, (2) variaciones de insolación, (3) variaciones de humedad y (4) variaciones de temperatura.

Otros factores paleoambientales abióticos derivados de la fragmentación debieron ser más importantes durante el neógeno que aquellos relacionados con el desarrollo de un relieve pronunciado. Estos otros factores están más relacionados con el aumento de la diversidad de los diferentes tipos de sustratos que debió generarse como producto de la acumulación de sedimentos y el desarrollo de suelos sobre ellos y por la diversidad de sustratos rocosos del basamento ígneo y metamórfico. Entre estos factores se pueden mencionar: (1) variación de la composición química y mineralógica de los suelos y sustratos rocosos; (2) estructura física del suelo, como los patrones de erosión y la fracturación o exfoliación, en el caso de los sustratos rocosos; (3) porosidad y permeabilidad y su relación con el drenaje; (4) textura de los suelos; (5) presencia o ausencia de perfiles de meteorización del basamento. Al mismo tiempo, estos factores también pueden influir para formar barreras ecológicas para las especies, sobre todo vegetales y generar refugios de especies poco frecuentes o en retracción por diversos factores (Larson et al., 2008).

\section{Conclusiones}

Se determinó la presencia de las especies de mamíferos fósiles Nopachtus cabrerai, Notiomastodon platensis y cf. Trigodon gaudryi en los depósitos pedemontanos de la vertiente oriental de las Sierras de Córdoba. La primera y la última de estas especies son registradas por primera vez en la región periserrana de las Sierras de Córdoba.

Nopachtus cabrerai y cf. Trigodon gaudryi se unen al conjunto de taxones que indican una clara conexión de las Sierras de Córdoba con la región Pampeana, de la misma manera que ocurre con los mamíferos fósiles del valle del río de La Cruz (Tauber et al., 2017).
Se determinó la presencia de la icnofacies de Scoyenia en la nueva localidad el río San Bartolomé que se interpretó como una llanura de inundación con depósitos de desborde o meandros abandonados sujetos a exposición subaérea y colonización de la flora y la fauna, en un clima árido a semiárido.

Los sedimentos neógenos de la región estudiada de la Barrancas de Los Loros y el río San Bartolomé se depositaron en sistemas fluviales con canales meandriformes, intercalados con palosuelos desarrollados en llanuras de inundación con depósitos de desborde o meandros abandonados.

El inició de la sedimentación neógena en la región de Alpa Corral (Asociación de facies A; valle del río de Las Barrancas y río San Bartolomé), en el borde occidental del piedemonte oriental de la Sierra de los Comechingones, habría comenzado durante el Plioceno temprano (Edad Montehermosense).

Se confirmaría una edad Pleistocena para la Asociación de facies B de la sección estudiada en río San Bartolomé, por la presencia del proboscideo Notiomastodon platensis.

Durante la primera etapa de formación de los depocentros neógenos, los factores ambientales relacionados con el gradiente de altitud no habrían incidido de una manera tan acentuada como sí pudo haber ocurrido en las etapas posteriores del levantamiento de los cordones montañosos, por ejemplo a partir del límite entre el Plioceno tardío y Pleistoceno Temprano.

El registro paleontológico y sedimentario analizado indica un diacronismo muy marcado entre el momento del inicio de la depositación neógena en las Sierras de Córdoba, con dirección general de oeste a este, coincidiendo con la dirección y sentido de la subducción horizontal de la placa de Nazca debajo de la placa Sudamericana. Este diacronismo se manifiesta por las diferentes antigüedades de los sedimentos en las distintas regiones, depositados inicialmente durante el Mioceno tardío (Edad Huayqueriense) en el sector sur del valle de San Alberto, el Plioceno temprano (Edad Montehermosense) en la región de Alpa Corral (Barrancas de Los Loros y río San Bartolomé) y el Plioceno tardío (Edad Chapadmalalense) en el valle del río de La Cruz.

\section{Agradecimientos}

Los autores desean expresar su agradecimiento a las siguientes personas, quienes colaboraron con este trabajo en distintas instancias: S. Centorbi, M. Fontanyi, U. D’Andrea, B. Nores, G. Pérez Álvarez, M. Martínez, 
P. Tauber, E. Borsini, F. Heredia y D. Alonso. Los revisores Dra. M.E. Pérez y el Dr. W. Vivallo, mejoraron significativamente este trabajo con sus observaciones y sugerencias. Las fotografías del material paleontológico fueron tomadas por M. Pizarro. Esta investigación no ha recibido financiamiento de fuente alguna.

\section{Referencias}

Alberdi, M.T.; Prado, J.L. 2008. Presencia de Stegomastodon (Gomphotheriidae, Proboscidea) en el Pleistoceno Superior de la zona costera de Santa Clara del Mar (Argentina). Estudios Geológicos 64 (2): 175e185. doi: 10.3989/egeol.08642.044.

Álvarez, D.; Tauber, A. 2003. Nuevos registros de mamíferos en la Formación Brochero (Plioceno temprano) del valle de Nono, Córdoba, República Argentina. In Jornadas Argentinas de Paleontología de Vertebrados, No. 19, Ameghiniana 40 (4) Resúmenes: 50R. Buenos Aires.

Álvarez, D.; Tauber, A. 2004. Vertebrados de la Formación Brochero (Mioceno tardío-Plioceno) de Córdoba, Argentina. In Jornadas Argentinas de Paleontología de Vertebrados, No. 20, Ameghiniana 41 (4) Resúmenes: 32R-33R. La Plata.

Alves, R.; Kolbek, J. 1994. Plant-species endemism in savanna vegetation on Table Mountains (camporupestre) in Brazil. Vegetatio 113: 125-139.

Ameghino, F. 1882. Catálogo explicativo de las colecciones de antropología prehistórica y de paleontología de Florentino Ameghino, partido de Mercedes. In Catálogo de la sección de la Provincia de Buenos Aires (República Argentina) en la exposición Continental Sud-Americana, Anexo A (Urioste, C.; Ambrosetti, T.; Butteler, B.; De Toledo, R.A.; Ruiz, F.; Lainez, M.; Schröder, E.; Quesada, H.; Duggan, M.; Araujo Muñoz, R.; editores). El Diario Imprenta: 35-42. San Martín.

Ameghino, F. 1888. Rápidas diagnosis de algunos mamíferos fósiles nuevos de la República Argentina. P.E. Coni: 1-17. Buenos Aires.

Ameghino, F. 1889. Contribución al conocimiento de los mamíferos fósiles de la República Argentina. Actas de la Academia Nacional de Ciencias 6: 1-1027. Córdoba.

Andreazzini, J.; Degiovanni, S. 2011. Diseño de canal en el sector pedemontano del río Las Cañitas, Córdoba. Factores de control, morfodinámica e implicancias ambientales. In Congreso Geológico Argentino, No. 18, Actas CD: 1426-1427. Neuquén.

Astini, R.A.; Tauber, A.; Marengo, H.G.; Oviedo, N.V. 2014. Cubierta sedimentaria Cenozoica (PaleógenoNeógeno). In Relatorio de la geología y recursos
Naturales de la Provincia de Córdoba (Martino, R.D.; Guereschi, A.B.; editores). Asociación Geológica Argentina: 539-589. Buenos Aires.

Asurmendi, I. 2015. Estratigrafía y vertebrados fósiles del Cenozoico tardío del río de La Cruz, departamento Calamuchita, provincia de Córdoba. Tesis de Grado (Inédito), Facultad de Ciencias Exactas, Físicas y Naturales, Universidad Nacional de Córdoba: 100 p.

Bann, K.L.; Tye, S.C.; MacEachern, J.A.; Fileding, C.R.; Jones, B.G. 2008. Ichnological and sedimentologic signatures of mixed wave- and storm-dominated deltaic deposits: Examples from the early Permian Sidney Basin, Australia. In Recent Advances in Models of Siliciclastic Shallow-Marine Stratigraphy (Hampson, G.; Steel, R.J.; Burgess, P.; Dalrymple, R.; editors). Society for Sedimentary Geology (SEPM) Special Publication 90: 293-332.

Barthlott, W.A.; Greger, A.; Porembski, A. 1993. Some remarks on the vegetation of tropical inselbergs: Diversity and ecological differentiation. Biogeographica 69: 106-124.

Beltramone, C.A. 2004. Caracterización estructural del piedemonte occidental de las sierras Chicas y de Pajarillo-Copacabana entre la Cumbre y Las Lajas, Provincia de Córdoba. Revista de la Asociación Geológica Argentina 59: 423-432.

Berman, W.D. 1994. Los carnívoros continentales (Mammalia, Carnivora) del Cenozoico en la Provincia de Buenos Aires. Tesis Doctoral (Inédito), Facultad de Ciencias Naturales y Museo, Universidad Nacional de La Plata: 413 p.

Bonalumi, A.; Martino, R.D.; Baldo, E.G.; Zarco, J.; Sfragulla, J.; Carignano, C.; Kraemer, P.; Escayola, M.; Tauber, A.; Cabanillas, A.; Juri, E.; Torres, B. 2000. Hoja Geológica 3166-IV, Villa Dolores, Provincias de Córdoba, La Rioja y San Luis. Servicio Geológico Minero Argentino, Instituto de Geología y Recursos Minerales (SEGEMAR), Programa Nacional de Cartas Geológicas Escala 1.250.000. Buenos Aires.

Bond, M. 1999. Quaternary native ungulates of southern South America. A synthesis. In Quaternary Vertebrate Paleontology in South America, Quaternary of South America and Antarctic Peninsula (Tonni, E.P.; Cione, A.L.; editors). Special Volume 12: 177-205.

Bond, M.; Cerdeño, E.; López, G. 1995. Los ungulados nativos de América del Sur. In Evolución biológica y climática de la Región Pampeana durante los últimos cinco millones de años: un ensayo de correlación con el Mediterráneo Occidental (Alberdi, M.T.; Leone, G.; Tonni, E.P.; editores). Museo Nacional de Ciencias Naturales, Monografías 12: 257-275. Madrid. 
Buatois, L.A.; Mángano, M.G. 1995. The paleoenvironment and paleoecological significance of the lacustrine Mermia ichnofacies: an achetypical subaqueous nonmarine trace fossil assemblage. Ichnos 4: 151-161.

Buatois, L.A.; Mángano, M.G.; Aceñolaza, F.G. 2002. Trazas fósiles. Señales de comportamiento en el Registro Estratigráfico. X Museo Egidio Feruglio (MEF), Edición Especial No. 2: 382 p.

Burke, A.; Esler, K.; Pienaar, E.; Barnard, P. 2003. Species richness and floristic relationships between mesas and their surroundings in southern African Nama Karoo. Diversity and Distributions 9: 43-53.

Burmeister, G. 1874. Monografía de los glyptodontes en el Museo Público de Buenos Aires. Anales del Museo Público de Buenos Aires 2 (6): I-IV + 355-412.

Cabrera, A. 1929. Una revisión de los Mastodontes Argentinos. Revista del Museo de La Plata 32: 61-144.

Caniggia, J. 2004. Estratigrafía y Paleontología del Pleistoceno Inferior y Medio de la provincia de Córdoba. Tesis de Grado (Inédito), Universidad Nacional de Córdoba: $129 \mathrm{p}$.

Cantero, J.J. 2018. Vida en las rocas: plantas rupícolas. FOLIUM Relatos botánicos 1: 24-35.

Cantero, J.J.; Barboza, G.E.; Núñez, C.; Volkmann, L.; Chiarini, F.; Bernardello, G.; Cabido, M., Ariza Espinar, L.; Mulko, J.; Morero, R.; Giorgis, M.; Demaio, P.; Amuchastegui, A.; Brandolín, P.; Deanna, R.; Leiva González, S.; Sfragulla, J.; Bonalumi, A.; Re, G. 2017a. Plantas rupícolas de Argentina central. Universidad Privada Antenor Orrego (UPAO): 498 p. Trujillo.

Cantero, J.J.; Mulko, J.; Núñez, C.; Zeballos, S.R.; Sfragulla, J.A.; Amuchastegui, A.; Barboza, G.E.; Chiarini, F.; Ariza Espinar, L.; Bonalumi, A.A.; Brandolin, P.; Cabido, M. 2017b. Heterogeneidad de la vegetación en ambientes basálticos del centro de Argentina. Boletín de la Sociedad Argentina de Botánica 52 (1): 153-183.

Cantero, J.J.; Núñez, C.; Mulko, J.; Brandolín, P.; Amuchastegui, A.; Sfragulla, J.A.; Bonalumi, A.A.; Martínez, A.N.; Zeballos, S.; Cabido, M.; Barboza, G.E.; Chiarini, F.; Ariza Espinar, L. 2016. Vegetación y flora de afloramientos basálticos del centro de Argentina. Arnaldoa 23 (1): 185-218.

Cantero, J.J.; Sfragulla, J.A.; Núñez, C.; Bonalumi, A.; Mulko, J.; Amuchastegui, A. 2014a. Relaciones vegetación-ambiente en hábitats amenazados del centro de Argentina: afloramientos de rocas carbonáticas cálcicas y dolomíticas. In Congreso Geológico Argentino, No. 19, Geoparques-Sitios de Interés Geológico: T13-03. Córdoba.
Cantero, J.J.; Sfragulla, J.A.; Núñez, C.; Bonalumi, A.; Mulko, J.; Amuchastegui, A. 2014b. Relaciones islamatriz circundante en la vegetación de los afloramientos basálticos del centro de Argentina. Geoparques-Sitios de Interés Geológico: T13-04. Córdoba.

Cantero, J.J.; Sfragulla, J.A.; Núñez, C.; Mulko, J.; Bonalumi, A.A.; Amuchastegui, A.; Barboza, G.E.; Chiarini, F.; Ariza Espinar, L. 2014c. Vegetación de afloramientos carbonáticos de montañas del centro de Argentina. Boletín de la Sociedad Argentina de Botánica 49 (4): 559-580.

Cantero, J.J.; Sfragulla, J.A.; Núñez, C.; Bonalumi, A.A.; Mulko, J.; Amuchastegui, A.; Chiarini, F.; Barboza, G.E.; Ariza Espinar, L. 2011. Flora de los afloramientos de mármoles y serpentinitas de las Sierras de Córdoba (Argentina). Kurtziana 36: 11-45.

Cantú, M.P. 1992. El Holoceno de la Provincia de Córdoba. In El Holoceno en la ArgentinaX (Iriondo, M.; editor), Comité Argentino de Investigaciones del Cuaternario (CADINCUA): 1-16. Buenos Aires.

Carignano, C.A.; Kröhling, D.; Degiovanni, S.; Cioccale, M.A. 2014. Geomorfología. In Relatorio de la geología y recursos Naturales de la Provincia de Córdoba (Martino, R.D.; Guereschi, A.B.; editores). Asociación Geológica Argentina: 747-822.

Castellanos, A. 1922. La presencia del hombre fósil en el Pampeano medio del valle de Los Reartes (Sierra de Córdoba). Boletín de la Academia Nacional de Ciencias 25: 369-374.

Castellanos, A. 1942. Los sedimentos prepampeanos del valle de Nono (Sierra de Córdoba) Argentina. Publicaciones del Instituto de Fisiografía y Geología 13: 1-62.

Castellanos, A. 1944. Paleontología estratigráfica de los sedimentos neógenos de la provincia de Córdoba. Publicaciones del Instituto de Fisiografía y Geología 23: $1-47$.

Castellanos, A. 1958. Nota preliminar sobre nuevos restos de mamíferos fósiles del Brocherense del valle de Los Reartes (Provincia de Córdoba, Argentina). In Congreso Geológico Internacional, No. 20, Actas 7 : 217-233. México.

Cione, A.L.; Gasparini, G.M.; Soibelzon, E.; Soibelzon, L.H.; Tonni, E.P. 2015. The Great American Biotic Interchange. A South American perspective. Springer Netherlands: 97 p. Amsterdam. doi: 10.1007/978-94017-9792-4.

Cione, A.L.; Tonni, E.P. 1995a. Bioestratigrafía y cronología del Cenozoico superior de la región pampeana. In Evolución Biológica y Climática de la Región Pampeana durante los últimos cinco millones de años 
(Alberdi, M.T.; Leone, G.; Tonni, E.P.; editores). Museo Nacional de Ciencias Naturales: 49-74. Madrid.

Cione, A.L.; Tonni, E.P. 1995b. Los estratotipos de los pisos Montehermosense y Chapadmalalense (Plioceno) del esquema cronológico sudamericano. Ameghiniana 32 (4): 369-374.

Cione, A.L.; Tonni, E.P.; 1995c. Chronostratigraphy and "Land-Mammal Ages" in the Cenozoic of southern South America: principles, practices, and the "Uquian" problem. Journal of Paleontology 69 (1): 135-159.

Cione, A.L.; Tonni, E.P. 2005. Biostratigrafía basada en mamíferos del Cenozoico superior de la provincia de Buenos Aires, Argentina. In Relatorio de la geología y recursos Naturales de la Provincia de Buenos Aires (De Barrio, R.E.; Etcheverry, R.O.; Caballé, M.F.; Llambías, E.; editores). Asociación Geológica Argentina: 183-200.

Combina, A.; Sánchez, M. 2003. Análisis sedimentológico de la Formación La Invernada, Pleistoceno TardíoHoloceno, pedemonte de las Sierras de Comechingones, Provincia de Córdoba, Argentina. Revista de la Asociación Argentina de Sedimentología 10 (2): 123-135.

Comité Argentino de Estratigrafia, 1992. Código Argentino de Estratigrafía. Asociación Geológica Argentina; Serie B (20): 64 p.

Cope, E.D. 1889. The Edentata of North America. The American Naturalist 23: 657-664.

Costa, C.; Massabie, A.; Sagripanti, G.; Brunetto, E.; Coppolecchia, M. 2014. Neotectónica de la provincia de Córdoba. In Relatorio de la geología y recursos Naturales de la Provincia de Córdoba (Martino, R.D.; Guereschi, A.B.; editores). Asociación Geológica Argentina: 725-748.

Costa, C.; Murillo, V.; Sagripanti, G.; Gardini, C. 2001. Quaternary intrapalate deformation in the southearstern Sierras Pampeanas, Argentina. Journal of Seismology 5: 399-409.

Costa, C.; Vita-Finzi, C. 1996. Late Holocene faulting in the Southeast Sierras Pampeanas of Argentina. Geology 24 (12): 1127-1130.

Cruz, L.E. 2013. Biostratigraphy and geochronology of the late Cenozoic of Córdoba Province (central Argentina). Journal of South American Earth Sciences 42: 250-259.

Cruz, L.E. 2011. La megafauna del Pleistoceno-Holoceno temprano de la Provincia de Córdoba y su comparación con la de Buenos Aires. Sistemática, bioestratigrafía y dinámica faunística. Tesis Doctoral (Inédito), Universidad Nacional de La Plata: 226 p.

Cruz, L.E.; Bargo, M.S.; Tonni, E.P.; Figini, A.J. 2010. Radiocarbon date on megafauna from the late
Pleistocene-early Holocene of Córdoba province, Argentina: stratigraphic and paleoclimatic significance. Revista Mexicana de Ciencias Geológicas 27 (3): 470-476.

Cruz, L.E.; Krapovickas, J.M.; Tauber, A.A. 2019. Paleontología de vertebrados y bioestratigrafía del Cuaternario de la provincia de Córdoba, Argentina. In Mioceno al Pleistoceno del Centro y Norte de Argentina (Nasif, N.; Esteban, G.; Chiesa, J.; Zurita, A.; Georgieff, S.; editores). Opera Lilloana 52: 466-489.

Cruz, L.E.; Fernícola, J.C.; Carignano, C.A. 2017. New Vertebrates of the Brochero Formation (Córdoba, Argentina): A Review of the Pliocene of Central Argentina. Journal of Mammalian Evolution 25: 315 326. doi: 10.1007/s10914-017-9390-0.

Dantas, M.A.T.; Dutra, R.P.; Cherkinsky, A.; Fortier, D.C.; Kamino, L.H.Y.; Cozzuol, M.A.; Ribeiro, A.S.; Silva, F.V. 2013. Paleoecology and radiocarbon dating of the Pleistocene megafauna of the Brazilian intertropical region. Quaternary Research 79: 61-65.

Degiovanni, S.; Villegas, M.; Blarasin, M.; Sagripanti, G. 2005. Hoja Geológica Río Cuarto-3263-III. Secretaría de Minería de la Nación-SEGEMAR: 90 p., 1 mapa.

De Lange, P.J.; Norton, D.A.; Heenan, P.B.; Courtney, S.P.; Molloy, B.P.J.; Ogle, C.C.; Rance, B.D.; Johnson, P.N.; Hitchmough, R. 2004. Threatened and uncommon plants of New Zealand. New Zealand Journal of Botany 42: 45-76.

Deschamps, M.C.; Tomassini, R.L. 2016. Late Cenozoic vertebrates from the southern Pampean Region: systematic and bio-chronostratigraphic update. In Palinología del Meso-Cenozoico de Argentina, Buenos Aires (Martínez, M.; Olivera, D.; editores). Publicación Electrónica de la Asociación Paleontológica Argentina 16: 202-225.

Esgario, C.P.; Fontana, A.P.; Silva, A.G. 2009. A flora vascular sobre rocha no Alto Misterioso, uma área prioritária para a conservação da Mata Atlântica no Espírito Santo, Sudeste do Brasil. Natureza on line 7: 80-91.

Frey, R.W.; Pemberton, S.G. 1987. The Psilonichnus ichnocoense, and its reltionship to adjacent marine and nonmarine ichocoenoses along the Georgia coast. Bulletin of Canadian Petroleum Geology 35: 333-357.

Frey, R.W.; Pemberton, S.G.; Fagerstrom, J.A. 1984. Morphological ethological and environmental significance of the ichnogenera Scoyenia and Ancorichnus. Journal of Paleontology 58: 511-528.

Friend, P.F.; Slater, M.J.; Williams, R.C. 1979. Vertical and lateral building of river sandstone bodies, Ebro 
Basin, Spain. Journal of the Geological Society of London 136: 39-46.

Gervais, H. 1847. Observations sur les mammmiféres fossiles du midi de la France. Annales des Sciences Naturelles, Zoologie 8 (3): 203-224.

Giannoncelli, R.M.; Tauber, A.A. 1997. Nueva localidad fosilífera del Plioceno en la Provincia de Córdoba, República Argentina. Reunión anual de comunicaciones de la Asociación Paleontológica Argentina. Ameghiniana 34 (1): 119.

Giulietti, A.M.; Harley, R.M.; De Queiroz, L.P.; Wanderley, M.G.L.; Van Den Berg, C. 2005. Biodiversity and conservation of plants in Brazil. Conservation Biology 19: 632-639.

Giulietti, A.M.; Pirani, J.; Harley, R.M. 1997. Espinhaço range region, eastern Brazil. In Centres of Plant Diversity: A Guide and Strategy for their Conservation (Davis, S.D.; Heywood, V.H.; Herrera-MacBryde, O.; Villa-Lobos J.; Hamilton A.C.; editors). International Union for Conservation of Nature (IUCN) Publication Unity 3: 397-404. Cambridge.

Gordillo, C.; Lencinas, A. 1979. Sierras Pampeanas de Córdoba y San Luis. In Geología Regional Argentina (Turner, J.C.; editor). Academia Nacional de Ciencias 1: 577-650. Córdoba.

Gray, J.E. 1821. On the natural arrangement of vertebrose animals. London Medical Repository 15: 296-310.

Gray, J.E. 1869. Catalogue of carnivorous, pachydermatous and edentates Mammalia in the British Museum. British Museum of Natural History: 1-398. Londres.

Hay, O.P. 1922. Further Observations on some extinct elephants. Proceedings of the Biological Society of Washington 35: 97-102.

Hunter, J.T. 2003. Persistence on inselbergs: the role of obligate seeders and resprouters. Journal of Biogeography 30: 497-510.

Illiger, J.K.W. 1811. Prodromus systematis mammalium et avium additis terminis zoographicis utriusque classis, p. 111. C. Salfeld: xviii + 201. Berlin.

Jacobi, C.M.; Do Carmo, F.F. 2008 a. Diversidade dos campos rupestres ferruginosos no Quadrilátero Ferrífero, MG. Megadiversidade 4: 25-33.

Jacobi, C.M.; Do Carmo, F.F. 2008 b. The contribution of ironstone outcrops to plant diversity in the Iron Quadrangle, a threatened Brazilian landscape. Ambio 37: 324-326.

Kraemer, P.; Tauber, A.; Schmidt, C.; Ramé, G. 1993. Análisis cinemático de la falla de Nono. Evidencias de actividad neotectónica, Valle de San Alberto. Provincia de Córdoba. In Congreso Geológico Argentino,
No. 12 y Congreso de Exploración de Hidrocarburos, No. 2, Actas 3: 277-281. Mendoza.

Kraglievich, L. 1934. La antigüedad pliocena de las faunas de Monte Hermoso y Chapadmalal, deducidas de su comparación con las que le precedieron y sucedieron. El Siglo Ilustrado: 1-136. Montevideo.

Krapovickas, J.M. 2014. Estratigrafía y mamíferos fósiles de las Sierras Pampeanas de la Provincia de Córdoba, Argentina. Tesis Doctoral (Inédito), Facultad de Ciencias Exactas, Físicas y Naturales, Universidad Nacional de Córdoba: 391 p.

Krapovickas, J.M.; Tauber, A.A. 2016. Estratigrafía de las áreas cumbrales de las Sierras Pampeanas de Córdoba: geocronología, modelo regional, paleoambiente y paleoclima en una región poco conocida de Argentina. Revista Mexicana de Ciencias Geológicas 33 (1): 105-121.

Krapovickas, J.M.; Tauber, A.A.; Haro, A. 2017. Quaternary biostratigraphy and biogeography of mountain region of Córdoba, Argentina. Geobios 50 (3): 211-236.

Kröhling, D.; Carignano, C.A. 2014. La estratigrafía de los depósitos sedimentarios cuaternarios. In Relatorio de la geología y recursos Naturales de la Provincia de Córdoba (Martino, R.D.; Guereschi, A.B.; editores). Asociación Geológica Argentina: 673-724. Buenos Aires.

Larson, D.; Matthes, U.; Kelly, P.E. 2008. Cliff ecology: pattern and process in cliff ecosystems. Cambridge Studies in Ecology. Cambridge University Press: 360 p. Cambridge.

López, G.; Reguero, M.; Lizuain, A. 2001. El registro más antiguo de mastodontes (Plioceno tardío) de América del Sur. In Jornadas Argentinas de Paleontología, No. 17, Ameghiniana 38 (Resúmenes): 35R-36R. Esquel.

Marshall, L.; Berta, A.; Hoffstetter, R.; Pascual, R.; Reig, O.A.; Bombin, M.; Mones, A. 1984. Mammals and stratigraphy: geochronology of the continental mammalbearing Quaternary of South America. Palaeovertebrata Mémoire Extraordinaire: 1-76.

MacEachern, J.A.; Pemberto, S.G.; Gingras, M.K.; Bann, K.L. 2010. Ichnology, and Facies Models. In Facies Models 4 (James, N.P.; Dalrymple, R.W.; editors). Geological Association of Canada: 19-58. San Juan de Terranova.

Marshall, L.G.; Hoffstetter, R.; Pascual, R. 1983. Mammals and stratigraphy: geochronology of the continental mammal-bearing Tertiary of South America. Palaeovertebrata Mémoire Extraordinaire: 1-93.

Martino, R.D.; Guereschi, A.B.; Carignano, C.C. 2012. Influencia de la tectónica Preandina sobre la tectónica Andina: El caso de la falla de la Sierra Chica, Sierras 
Pampeanas de Córdoba. Revista de la Asociación Geológica Argentina 69 (2): 207-221.

Martino, R.D.; Guereschi, A.B.; Montero, A.C. 2014. La estructura cenozoica (paleógena-neógena) de las sierras de Córdoba. In Relatorio de la geología y recursos Naturales de la Provincia de Córdoba (Martino, R.D.; Guereschi, A.B.; editores). Asociación Geológica Argentina: 649-671. Buenos Aires.

Miall, A.D. 2006. The geology of fluvial deposits: sedimentary facies, basin analysis, and petroleum geology. Springer-Verlag: 582 p. Berlin.

Miall, A.D. 2010. Alluvial Deposits. In Facies Models 4 (James, N.P.; Dalrymple, R.W.; editores). Geological Association of Canada: 105-137. San Juan de Terranova.

Michelangeli, F.A. 2000. Species composition and speciesarea relationships in vegetation isolates on summit of a sandstone mountain in southern Venezuela. Journal of Tropical Ecology 16: 69-82.

Montes, A. 1960. El hombre fósil de Miramar (Córdoba). Revista de la Facultad de Ciencias Exactas, Físicas y Naturales, Universidad Nacional de Córdoba 21 (1-2) 42: 1-29.

Mothé, D.; Avilla, L.S.; Asevedo, L.; Borges-Silva, L.; Rosas, M.; Labarca-Encina, R.; Souberlich, R.; Soibelzon, E.; Roman-Carrion, J.L.; Ríos, S.D.; Rincon, A.D.; Cardoso de Oliveira, G.; Lopes, R.P. 2017. Sixty years after 'The mastodonts of Brazil': The state of the art of South American proboscideans (Proboscidea, Gomphotheriidae). Quaternary International 443: 52-64.

Mothé, D.; Avilla, L. 2015. Mythbusting evolutionary issues on South American Gomphotheriidae (Mammalia: Proboscidea). Quaternary Science Reviews 110: 23-35.

Owen, R. 1853. Description of some species of the extinct genus Nesodon, with remarks on the primary group (Toxodontia) of hoofed quadrupeds, to which that genus is referable. Philosophical Transactions of the Royal Society of London 143: 291-310.

Poma, S.; Ramos, A.; Litvak, V.D.; Quenardelle, S.; Maisonnave, E.B.; Díaz, I. 2017. Southern Central Andes Neogene magmatism over the Pampean Flat Slab: implications on crustal and slab melts contribution to magma generation in Precordillera, Western Argentina. Andean Geology 44 (3): 249-274. doi: 10.5027/andgeoV44n3-a02.

Porembski, S.; Szarzynski, J.; Mund, J.P.; Barthlott, W. 1996. Biodiversity and vegetation of smallsized inselbergs in aWest African rain forest (Taï, Ivory Coast). Journal of Biogeography 23: 47-55.

Porembski, S.; Barthlott, W.; Dörrstock, S.; Biedinger, N. 1994. Vegetation of rock outcrops in Guinea: granite inselbergs, sandstone table mountains and ferricretesremarks on species numbers and endemism. Flora 189: 315-326.

Prado, J.L.; Arroyo-Cabrales, J.; Johnson, E.; Alberdi, M.T.; Polaco, O.J. 2015. New World proboscidean extinctions: comparisons between North and South America. Archaeological and Anthropological Sciences 7: 277-288.

Ramos, V.A.; Folguera, A. 2016. Andean flat-slab subduction through time. In Ancient Orogens and Modern Analogues (Murphy, J.B.; Keppie, J.D.; Hynes, A.J.; editors). Geological Society, Special Publications 327: 31-54. London.

Retallack, G.J. 2001. Soils of the past: an introduction to Paleopedology. $2^{\mathrm{a}}$ ed. Blackwell Science: 404 p. Oxford.

Rey Ocampo, M.J. 2015. Paleoambiente y vertebrados fósiles del Cenozoico tardío del departamento Río Cuarto, provincia de Córdoba. Trabajo Final (Inédito), Universidad Nacional de Córdoba: 110 p.

Richardson, T. 2011. A geophysical and geologic analysis of the development, structure, and activity of the eastern Sierras Pampeanas, Argentina. Tesis de Maestría, Department of Earth, Atmosphere and Planetary Scienses, Purdue University: 169 p. Indiana.

Richardson, T.; Ridgway, K.D.; Gilbert, H.; Martino, R.D.; Enkelmann, E.; Anderson, M.; Alvarado, P. 2013. Neogene and Quaternary tectonics of the Eastern Sierras Pampeanas, Argentina: Active intraplate deformation inboard of flat-slab subduction. Tectonics 32: 1-17.

Rogers, G.; Walker, S. 2002. Taxonomic and ecological profiles of rarity in the New Zealand vascular flora. New Zealand Journal of Botany 40: 73-93.

Roth, S. 1903. Los ungulados sudamericanos. Anales del Museo de La Plata, Paleontología 5: 1-36.

Rovereto, C. 1914. Los estratos araucanos y sus fósiles. Anales del Museo Nacional de Historia Natural de Buenos Aires 25: 1-250.

Sadler, K.D.; Bradfield, G.E. 2010. Ecological facets of plant species rarity in rock outcrop ecosystems of the Gulf Islands, British Columbia. Botany 88: 429-434.

Sagripanti, G.L.; Villalba, D.; Villegas, M. 2012. Nuevas evidencias de deformaciones cuaternarias asociadas a la falla Sierra Chica, sierras pampeanas de Córdoba. Revista de la Asociación Geológica Argentina 69 (4): 611-626. Buenos Aires.

Sanabria, J.; Argüello, G. 2003. Aspectos geomorfológicos y estratigráficos en la génesis y evolución de la Depresión Periférica, Córdoba (Argentina). In Congreso Argentino de Cuaternario y Geomorfología, No. 2, Actas 1: 177-184. Tucumán. 
Santa Cruz, J. 1973. Cortes geológicos transversales del valle del río Santa Catalina (Córdoba) en el sector del pie de sierra. Boletín de la Asociación Geológica de Córdoba, Actas 2 (1-2): 25-28.

Santa Cruz, J. 1972. Geología al Este de las Sierras Chicas (Provincia de Córdoba), Valle del río Primero. In Congreso Geológico Argentino, No. 5, Actas 1 (3-4): 102-109. Carlos Paz.

Sayago, J.M. 1978. Geomorfología del valle de "San Alberto", Provincia de Córdoba. In Congreso Geológico Argentino, No 7, Actas 2: 89-107. Neuquén.

Simpson, C.; Whitmeyer, S.; De Paor, D.G.; Gromet, L.P.; Miro, R.; Krol, M.A.; Short, H. 2001. Sequential ductile through brittle reactivation of major fault zones along the accretionary margin of Gondwana in Central Argentina. Geological Society, Special Publications 186: 233-255. London.

Smith, J.M.B.; Cleef, A.M. 1988. Composition and origins of the world's tropical pine floras. Journal of Biogeography 15: 631-645.

Soibelzon, E. 2008. Los Mamíferos del Ensenadense (Pleistoceno Inferior-Medio) del Este de la Region Pampeana, con enfasis en los Xenarthra. Bioestratigrafía, Diversidad y Correlaciones Biogeograficas. Tesis Doctoral (Inédito), Universidad Nacional de La Plata: 304 p.

Suriano, J.; Mardonez, D.; Mahoney, J.B.; Mescua, J.F.; Giambiagi, L.B.; Kimbrough, D.; Lossada, A. 2017. Uplift sequence of the Andes at 30S: Insights from sedimentology and $\mathrm{U} / \mathrm{Pb}$ dating of synorogenic deposits. Journal of South American Earth Sciences 75: 11-34

Tauber, A.A. 2000. Las Caleras, provincia de Córdoba, primer yacimiento fosilífero de origen cárstico de Argentina. Revista Española de Paleontología 15 (2): 233-244

Tauber, A.A.; Goya, F. 2006. Estratigrafía y fósiles del Pleistoceno-Holoceno de las pampas de altura en el departamento Cruz del Eje, Córdoba, Argentina. In Congreso Argentino de Cuaternario y Geomorfología 3, Actas II: 717-726. Córdoba.

Tauber, A.A.; Krapovickas, J.M.; Cruz, L.E.; Chiesa, J.O, 2019a. Estratigrafía, Paleontología y Paleoambientes del Plioceno de la Provincia de Córdoba. In Mioceno al Pleistoceno del Centro y Norte de Argentina (Nasif, N.; Esteban, G.; Chiesa, J.; Zurita, A.; Georgieff, S.; editores). Opera Lilloana No. 52: 389-417. Tucumán.

Tauber, A.A.; Álvarez, F.; Haro, A.; Krapovickas, J.; Centorbi, S.; Martínez, G.; Nieto, G.; Imbarratta, N. 2019b. Bioestratigrafía de vertebrados y evolución geológica del Cenozoico tardío en el área de Alpa Corral, Departamento Río Cuarto, Provincia de Córdoba, Argentina. In Jornadas Argentinas de Paleontología de Vertebrados, No. 33, Libro de Resúmenes: p. 81. Córdoba.

Tauber, A.; Haro, A.; Martínez, G.; Nieto, G.; Krapovickas, J. 2019c. El registro de Proterotheriidae en la Formación Brochero (Mioceno tardío - plioceno) de las Sierras Pampeanas de Córdoba, Argentina. In Simposio del Mioceno-Pleistoceno del Centro y Norte de Argentina, No. 5, Acta de Resúmenes: 107-110. San Salvador de Jujuy.

Tauber, A.A.; Álvarez, D.; Álvarez, F.; Centorbi, S.; Haro, J. A.; Krapovickas, J.M.; Imbarratta, N.; Pizarro, M.A.; Nieto, G. 2018. Nuevos registros de mamíferos en la Formación Brochero (Mioceno tardío-Plioceno) en su área tipo, Córdoba, Argentina. In Jornadas Argentinas de Paleontología de Vertebrados, No. 32 y Jornadas Técnicas de Paleontología de Vertebrados, No. 7, Resúmenes 19 (1): R33. Corrientes.

Tauber, A.A.; Asurmendi, I.; Krapovickas, J.M. 2017. Bioestratigrafía de vertebrados y evolución geológica del Cenozoico tardío del Valle de La Cruz, Córdoba, Argentina. Revista Brasileira de Paleontologia 20 (2): 219-238.

Tauber, A.A.; Krapovickas, J.M.; Marengo, H.; Haro, A. 2014. Paleontología del Cenozoico. In Relatorio de la geología y recursos Naturales de la Provincia de Córdoba (Martino, R.D.; Guereschi, A.B.; editores). Asociación Geológica Argentina: 591-621. Buenos Aires.

Tomassini, R.L. 2012. Estudio taxonómico y bioestratigráfico de los vertebrados de la Formación Monte Hermoso (Plioceno) en su localidad tipo, provincia de Buenos Aires. Tesis Doctoral (Inédito), Universidad Nacional del Sur: 300 p.

Tomassini, R.; Montalvo, C.; Deschamps, C.; Manera, T. 2013a. Biostratigraphy and biochronology of the Monte Hermoso Formation (early Pliocene) at its type locality, Buenos Aires Province, Argentina. Journal of South American Earth Sciences 48: 31-42.

Tomassini, R.L.; Montalvo, C.I.; Zárate, M.A.; Deschamps, C.M.; Vucetich, M.G. 2013b. Ventanas temporales, un concepto útil en el análisis biocronoestratigráfico del Mioceno tardío-Plioceno temprano de Argentina. In Simposio del Mioceno-Pleistoceno del Centro y Norte de Argentina, No. 2, Actas: 27. Diamante.

Wardle, J. 1971. The forests and shrublands of the Seaward Kaikoura Range. New Zealand Journal of Botany 9: 269-292. 
Wardle, P. 1991. Vegetation of New Zealand. Cambridge University Press: 672 p. Cambridge.

Wiser, S.K.; Buxton, R.P. 2009. Montane outcrop vegetation of Banks Peninsula, South Island, New Zealand. New Zealand Journal of Ecology 33: 164-176.

Zamorano, M. 2012a. Los Panochthini (Xenarthra, Glyptodontidae): Sistemática y evolución. Tesis Doctoral (Inédito), Universidad Nacional de La Plata: 269 p.

Zamorano, M. 2012b. Los Panochthini (Xenarthra, Glyptodontidae): Sistemática y evolución. Mastozoología Neotropical 19: 382-384.

Zamorano, M.; Moreno, G.G.; Vaccari, N.E.; Falcón, C.M.; Combina, A.M.; Bonini, R.A. 2017. Primer registro de Nopachtus coagmentatus (Xenarthra, Glyptodontidae) para la Provincia de Catamarca, Argentina. Revisión del género Nopachtus. Estudios Geológicos 73(2): e067.
Zamorano, M.; De los Reyes, M.; Poiré, D.G.; ScillatoYané, G.J. 2015. Primer registro fehaciente de Nopachtus coagmentatus (Xenarthra, Cingulata, Glyptodontidae) en la región Pampeana, Argentina. Contexto estratigráfico. Estudios Geológicos 71 (1): e027.

Zamorano, M.; Toriño, P.; Rinderknecht, A.; Perea, D. A. 2016. Primeros registros del género Nopachtus (Xenarthra: Cingulata: Glyptodontidae) en Uruguay. Revista Mexicana de Biodiversidad 87: 62-67.

Zamorano, M.; Scillato-Yané, G.J.; González Ruiz, L.R.; Zurita, A. 2011. Revisión de los géneros Nopachtus Ameghino y Phlyctaenopyga Cabrera (Xenarthra, Glyptodontidae, Hoplophorinae) del Mioceno tardío y Plioceno de Argentina. Revista del Museo Argentino Ciencias Naturales 13 (1): 59-68.

Manuscrito recibido: Diciembre 19, 2019; revisado/aceptado: Mayo 27, 2021; disponible en línea: Septiembre 30, 2021. 